\title{
Resiliência da diversidade de espécies florestais em áreas experimentais na Amazônia oriental brasileira
}

\author{
Resilience of the diversity of forest species in experimental areas in the eastern Brazilian Amazon \\ Resiliencia de la diversidad de especies forestales en áreas experimentales en la Amazonía oriental \\ brasileña
}

Recebido: 26/04/2021 | Revisado: 04/05/2021 | Aceito: 16/10/2021 | Publicado: 18/10/2021

Francimary da Silva Carneiro

ORCID: https://orcid.org/0000-0002-1693-8779

Universidade Federal Rural da Amazônia, Brasil

E-mail: francimarycarneiro@gmail.com

Ademir Roberto Ruschel

ORCID: https://orcid.org/0000-0002-0352-5238

Embrapa Amazônia Oriental, Brasil

E-mail: ademir.ruschel@embrapa.br

Francisco De Assis Oliveira

ORCID: https://orcid.org/0000-0002-4720-3492

Universidade Federal Rural da Amazônia, Brasil

E-mail: fdeassis@gmail.com

Marinalva Cardoso Maciel

ORCID: https://orcid.org/0000-0002-8670-8215

Universidade Federal do Pará, Brasil

E-mail: marinalvamaciel@gmail.com

Klewton Adriano Oliveira Pinheiro

ORCID: https://orcid.org/0000-0003-2696-4249 Instituto Federal do Pará, Brasil

E-mail: klewton.pinheiro@gmail.com

Larissa Martins Barbosa D'arace

ORCID: https://orcid.org/0000-0002-8533-555X

Universidade Federal Rural da Amazônia, Brasil E-mail: larissamartins350@gmail.com

Mario Lima dos Santos

ORCID: https://orcid.org/0000-0003-1679-9796

Universidade de Brasília, Brasil

E-mail: mariolimaeng@gmail.com

\begin{abstract}
Resumo
O objetivo deste trabalho foi avaliar a resiliência florestal, quanto a diversidade, em quatro áreas experimentais na Amazônia oriental brasileira. Como hipótese, espera-se que a floresta tropical de terra firme recupere a suas caracteristicas arbórea em um ciclo de 30 anos. Os dados foram coletados em quatro áreas distribuídas na Amazônia oriental Brasileira, sendo nos estados do Amapá e Pará. A maior parte dos tratamentos que foram monitorados antes da exploração florestal nas quatro áreas tiveram perda de espécies após a exploração florestal de impacto reduzido. Após os tratamentos silviculturais foi observado que a perda de espécies é maior, devido a retirada proposital de espécies que não são de interesse econômico para serrarias, porém de grande importância para o equilíbrio florestal. Após o fogo acidental foi constatado que o mesmo não alterou o número de espécies nos tratamentos em que tiveram o maior número de parcelas prejudicadas. A similaridade da floresta muda independente de ter sido uma área explorada ou não, a exploração florestal acelera essa mudança e cada tratamento tem a sua participação nesse contexto. A floresta tem resiliência em relação ao número de espécie, e a mesma tem uma variação de 3 a 30 anos após exploração florestal.
\end{abstract}

Palavras-chave: Similaridade florestal; Floresta equatorial; Tratamentos silviculturais; Manejo florestal.

\begin{abstract}
The objective of this work was to evaluate forest resilience, in terms of diversity, in four experimental areas in the eastern Brazilian Amazon. As a hypothesis, it is expected that the upland rainforest will recover its arboreal characteristics in a 30-year cycle. The data were collected in four areas distributed in the eastern Brazilian Amazon, being in the states of Amapá and Pará. Most of the treatments that were monitored before logging in the four areas had species loss after logging with reduced impact. After the silvicultural treatments, it was observed that the loss of species is greater, due to the deliberate removal of species that are not of economic interest for sawmills, but of great
\end{abstract}


importance for the forest balance. After the accidental fire, it was found that it did not change the number of species in the treatments in which they had the greatest number of damaged plots. The similarity of the forest changes regardless of whether it has been explored or not, forest exploitation accelerates this change and each treatment has its share in this context. The forest has resilience in relation to the number of species, and it varies from 3 to 30 years after logging.

Keywords: Forest similarity; Equatorial forest; Silvicultural treatments; Forest management.

\section{Resumen}

El objetivo de este trabajo fue evaluar la resiliencia forestal, en términos de diversidad, en cuatro áreas experimentales en la Amazonía oriental brasileña. Como hipótesis, se espera que la selva de montaña recupere sus características arbóreas en un ciclo de 30 años. Los datos fueron recolectados en cuatro áreas distribuidas en la Amazonía oriental brasileña, siendo en los estados de Amapá y Pará, la mayoría de los tratamientos que fueron monitoreados antes de la tala en las cuatro áreas tuvieron pérdida de especies luego de la tala con impacto reducido. Luego de los tratamientos silvícolas, se observó que la pérdida de especies es mayor, debido a la remoción deliberada de especies que no son de interés económico para los aserraderos, pero de gran importancia para el equilibrio forestal. Tras el incendio accidental, se constató que no modificó el número de especies en los tratamientos en los que tenían mayor número de parcelas dañadas. La similitud del bosque cambia independientemente de que haya sido explorado o no, la explotación forestal acelera este cambio y cada tratamiento tiene su parte en este contexto. El bosque tiene resiliencia en relación al número de especies y varía de 3 a 30 años después de la tala.

Palabras clave: Similitud forestal; Bosque ecuatorial; Tratamientos silvícolas; Gestión de bosques.

\section{Introdução}

A diversidade florestal é fundamental para o equilíbrio e manutenção do ecossistema amazônico, sendo sinônimo de riqueza e abundância de espécies no tempo e no espaço (Magurran, 2011). Devido a importância dos serviços ecossistêmicos oferecidos pela floresta para a vida e também sua utilidade para o setor madeireiro, o meio científico busca sempre equilibrar esse contexto, elucidando algumas características da floresta antes e pós colheita para um melhor uso deste ecossistema (Silva, 2004; Oliveira et al, 2005, Pinheiro et al. 2020, Pinheiro et al. 2021, Costa et al. 2021). Fatores que vão desde ordem natural até ação antrópica podem influenciar o processo de regeneração e a composição florística de uma floresta (Carneiro, 2016, Carneiro et al 2019, Carneiro et al, 2020, Coutinho et al, 2021).

Durante a década de 70, foram feitas as primeiras explorações planejadas e mecanizadas na Amazônia oriental Brasileira, onde todas as árvores comerciais com diâmetro a altura do peito (DAP) maiores que $45 \mathrm{~cm}$ de diâmetro eram colhidas, onde essas explorações serviram para motivar os experimentos da Embrapa Amazônia oriental em duas áreas florestais durante a década de 80, uma no Km 114 (1982) no estado do Pará e outra na Floresta do Jari ( 1984) no estado do Amapá, sendo utilizados vários tratamentos incluindo diferentes intensidade de corte (IC), diâmetro mínimo de corte (DMC), redução de áreas basais e diferentes tratamentos silviculturais(Carneiro, 2016).

Com os resultados deste monitoramento, foi feita outra exploração experimental na década de 90 no município de Moju sem tratamentos e outra na década de 2000 no município de Paragominas com tratamentos pós colheita, ambas no estado do Pará. Após a extração de madeira é importante estudos da dinâmica da floresta a fim de avaliar os impactos causados pela mesma, bem como para acompanhar o processo de restabelecimento da floresta (Castro \& Carvalho, 2014), sendo fundamentais para embasar quaisquer iniciativas de preservação e conservação dos remanescentes florestais (Regô et. al., 2015). O resultado do monitoramento continua contribuíram para a atual legislação florestal Brasileira, a qual prioriza a exploração de impacto reduzido e o manejo florestal sustentável (Carneiro, 2016).

Os impactos causados sobre a diversidade florística por essas práticas, já são estudados na região amazônica, ambos isoladamentes (Silva at al 1995, Oliveira et al 2005, Oliveira et al 2006, Sist e Ferreira 2007, Mazzei et al. 2010). Uma recomendação de práticas de manejo sustentável para a floresta amazônica, requer uma melhor compreensão dos impactos a longo prazo em toda a região (Silva et al 1995, Carvalho et al 2004, Carvalho 2012). Definir modalidades e intensidades de corte em função das características regionais da floresta amazônica constitui um desafio, devido a dificuldade de acesso a 
informação de vários sítios para representar a região.

Neste contexto, objetivamos avaliar a resiliência a florestal quanto a diversidade florestal em quatro áreas experimentais na Amazônia oriental brasileira para ver se as florestas recuperam a sua característica arbórea em um ciclo de 30 anos.

\section{Metodologia}

\section{Áreas de estudo}

Os dados foram coletados em quatro áreas distribuídas na Amazônia Oriental Brasileira, uma localizada no estado do Amapá, município de Vitória do Jari, na linha que limita esse estado ao estado do Pará. As outras três áreas estão no estado do Pará, sendo uma a oeste, outra no nordeste e outra no sudeste desta região.

Figura 1. Mapa de localização das áreas experimentais da Embrapa.

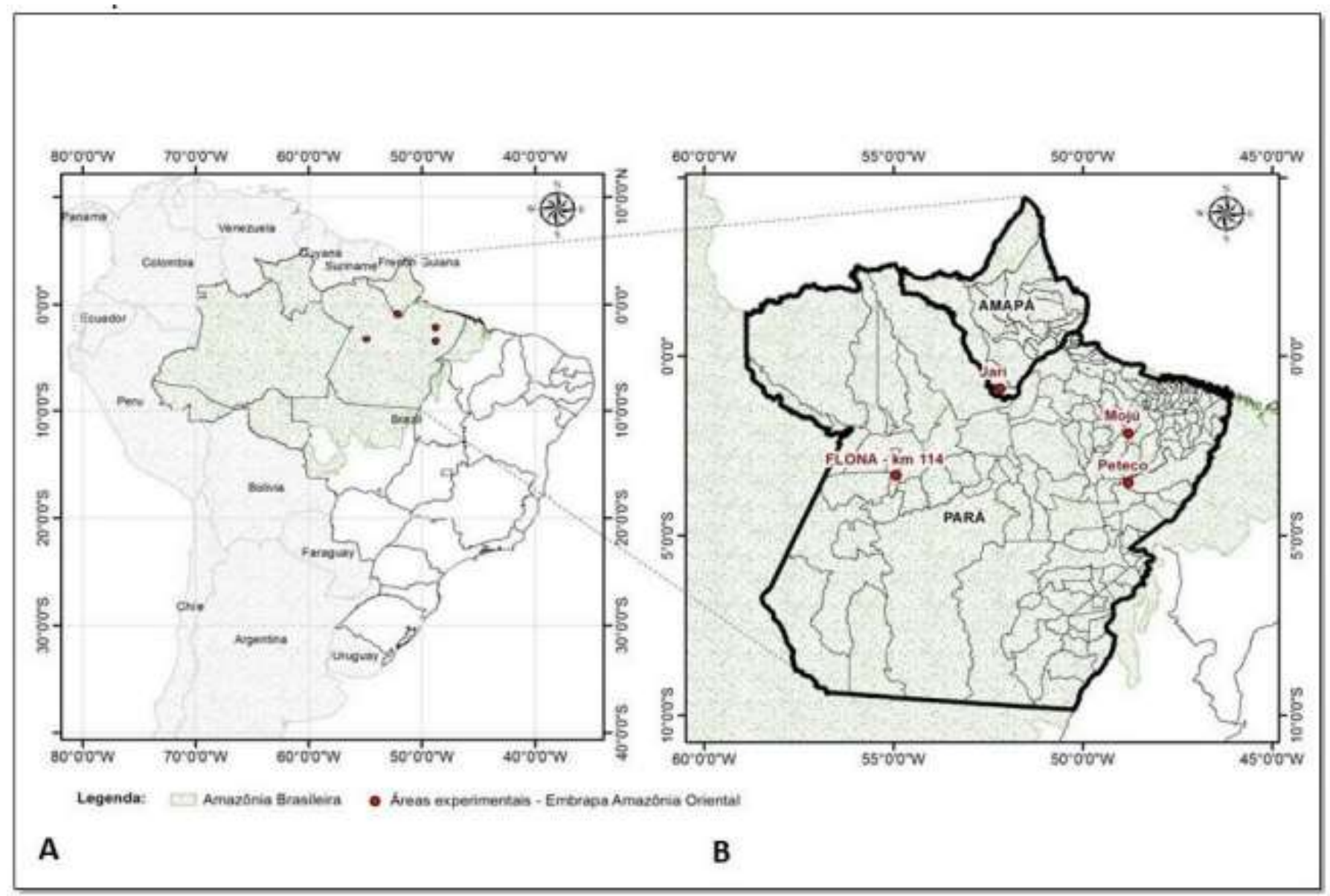

Fonte: Autores.

\section{Flona do Tapajós}

Esta área está localizada na Floresta Nacional do Tapajós, as proximidades do km 114 da BR 163, Rodovia Santarém-

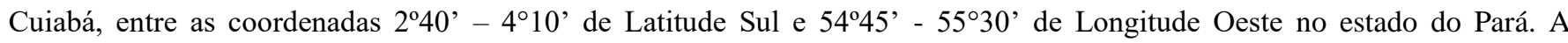
topografia da região é plana a ligeiramente ondulada e a altitude é de cerca de $175 \mathrm{~m}$ acima do nível do mar. O clima da região é tropical úmido, do tipo Ami com temperatura média anual de $25,5^{\circ} \mathrm{C}$ e umidade relativa média de $90 \%$ de acordo com a classificação de Köppen (Alvares et al., 2013). Nessa região, há predominância de Latossolo Amarelo Distrófico, perfil profundo e baixa fertilidade, caracterizados por textura muito argilosa, e revestido por florestas densas. A vegetação da área de 
estudo é classificada como Floresta Ombrófila Densa, caracterizando-se por indivíduos arbóreos de grande porte e pela presença de lianas lenhosas, palmeiras e epífitas emergentes e cobertura arbórea uniforme (IBGE 2012; Ivanauskas e Assis 2012).

Em 1981, foi implantado o experimento com um censo florestal e utilizando o delineamento de blocos ao acaso (DBC) com quatro repetições e quatro tratamentos (Tabela 1), totalizando 144 ha de área, sendo instaladas 48 parcelas permanentes retangulares de 0,25ha cada, ao mesmo tempo houve o corte de lianas. Em 1982 houve a exploração florestal, com a retirada de $73 \mathrm{~m}^{3} \cdot \mathrm{ha}^{-1}$, em média 12,5 árvores.ha ${ }^{-1}$ pertencentes a 38 espécies comerciais na época. Em $1983 \mathrm{em}$ um bloco de 36 ha foi adicionado o tratamento T0, representado pela floresta sem nenhuma intervenção. Em 1994, doze anos após a exploração florestal, foram aplicados os tratamentos silviculturais, eliminando árvores de espécies não comerciais na época, com a finalidade de reduzir a área basal do povoamento e, com isso, reduzir a competição entre árvores por luz, espaço e nutrientes, proporcionando o aumento da sobrevivência, crescimento e estabelecimento da regeneração natural das espécies de valor comercial (Oliveira et al., 2005). No final do ano de 1996 até o início de 1997, houve um incêndio na área, atingindo 19 das 60 parcelas instaladas, sendo seis parcelas do tratamento T0 (1,5ha), duas do tratamento T1 (0,5ha), cinco do tratamento $\mathrm{T} 2$ (1,25ha) e seis do tratamento T4 (1,5ha), essas parcelas foram utilizadas neste estudo.

Tabela 1. Tratamentos utilizados na Flona do Tapajós.

\begin{tabular}{|c|c|c|}
\hline $\begin{array}{l}\text { Tratamento } \\
\text { Silvicultural }\end{array}$ & Ano & Descrição dos Tratamentos Silviculturais \\
\hline \multirow[t]{2}{*}{ T0 } & 1983 & Instalação do tratamento sem nenhuma intervenção humana \\
\hline & 1996 & Fogo acidental atingindo metade das parcelas do tratamento \\
\hline \multirow[t]{2}{*}{ T1 } & 1982 & $\begin{array}{l}\text { Colheita de árvores com DAP } \geq 45 \mathrm{~cm} \text {, este tratamento reduziu a área basal em torno de } 24 \% \text { do } \\
\text { original. }\end{array}$ \\
\hline & 1996 & Fogo acidental atingindo duas parcelas do tratamento \\
\hline \multirow[t]{3}{*}{$\mathbf{T 2}$} & 1983 & $\begin{array}{l}\text { Colheita de árvores comerciais com DAP } \geq 55 \mathrm{~cm} \text {, este tratamento procurou reduzir a área basal } \\
\text { em } 20 \% \text { do original. }\end{array}$ \\
\hline & 1994 & $\begin{array}{l}\text { Anelamento com desvitalização de todas as árvores de espécies não comerciais com DAP } \geq 45 \\
\mathrm{~cm} \text {. }\end{array}$ \\
\hline & 1996 & Fogo acidental atingindo cinco parcelas do tratamento \\
\hline \multirow[t]{2}{*}{ T3 } & 1983 & $\begin{array}{l}\text { Colheita de árvores comerciais com DAP } \geq 55 \mathrm{~cm} \text { potenciais com DAP } \geq 65 \mathrm{~cm} \text {, redução da área } \\
\text { basal em } 40 \% \text { do original. }\end{array}$ \\
\hline & 1994 & $\begin{array}{l}\text { Anelamento com desvitalização de todas as árvores de espécies não comerciais com DAP } \geq 15 \\
\mathrm{~cm} \text { e espécies potenciais com DAP } \geq 65 \mathrm{~cm} \text {. }\end{array}$ \\
\hline \multirow[t]{3}{*}{ T4 } & 1983 & $\begin{array}{l}\text { Colheita de árvores comerciais com DAP } \geq 55 \mathrm{~cm} \text { visando a redução da área basal em } 60 \% \text { do } \\
\text { original. }\end{array}$ \\
\hline & 1994 & $\begin{array}{l}\text { Anelamento com desvitalização de todas as árvores de espécies não comerciais e potenciais com } \\
\mathrm{DAP} \geq 15 \mathrm{~cm} \text {, com exceção do Tauari e do Pau-rosa, }\end{array}$ \\
\hline & 1996 & Fogo acidental atingindo seis parcelas do tratamento \\
\hline
\end{tabular}

Fonte: Autores.

\section{Companhia Florestal Monte Dourado- Jari}

A área Experimental da Jari está delimitada em uma área de 500 ha de floresta densa na Companhia Florestal Monte Dourado (Jari), na localidade Morro do Felipe, município de Vitória do Jari, no estado do Amapá. A tipologia florestal é Floresta Ombrófila Densa. As coordenadas geográficas é $52^{\circ} 20^{\prime \prime} \mathrm{W}$ e $00^{\circ} 55^{\prime \prime} \mathrm{S}$. O clima é Am. Temperatura é $25,8^{\circ} \mathrm{C}$, a topografia é plano levemente ondulado, o tipo de solo é latossolo amarelo distrófico com textura argilosa pesada.

O experimento foi iniciado em 1983, com a realização do censo florestal e instalação dos tratamentos (Tabela 2). Em 1985 foi realizada a exploração florestal na área, Em 1994 foram aplicados os tratamentos silviculturais com dois tipos de desbaste, sendo um sistemático, com duas intensidades de redução da área basal original em 30\% e 50\%, e o outro seletivo. 
Em 400ha de floresta, foram instalados três blocos experimentais de 48 ha ambos com bordaduras e faixas com distancia de um km entre os blocos e as estradas. Nos 100 ha de floresta que não foram explorados, foram instalados quatro blocos de 1 ha cada, que são utilizados como testemunha.

O delineamento experimental foi estruturado em blocos ao acaso, com 13 tratamentos, sendo que, doze tratamentos possuem três repetições, e a testemunha possui quatro repetições.

Tabela 2. Tratamentos utilizados na Companhia Florestal Monte Dourado-Jari.

\begin{tabular}{|c|c|c|}
\hline $\begin{array}{l}\text { Tratamento } \\
\text { Silvicultural } \\
\end{array}$ & Ano & Descrição dos tratamentos silviculturais \\
\hline T0 & 1985 & Floresta sem nenhuma intervenção \\
\hline $\mathrm{T} 1$ & 1985 & $\begin{array}{l}\begin{array}{l}\text { Exploração de } 15 \% \text { do volume total das árvores de DAP > } 60 \mathrm{~cm} \text {, sem redução da área basal após a } \\
\text { exploração. }\end{array}\end{array}$ \\
\hline \multirow{2}{*}{$\mathrm{T} 2$} & 1985 & Exploração de $15 \%$ do volume total das árvores de DAP > $60 \mathrm{~cm}$. \\
\hline & 1994 & Redução de $30 \%$ da área basal original através de tratamentos silviculturais. \\
\hline \multirow{2}{*}{ T3 } & 1985 & Exploração de $15 \%$ do volume total das árvores de DAP > $60 \mathrm{~cm}$. \\
\hline & 1994 & Redução de $50 \%$ da área basal original através de tratamentos silviculturais. \\
\hline \multirow{2}{*}{$\mathrm{T} 4$} & 1985 & Exploração de $15 \%$ do volume total das árvores de DAP > $60 \mathrm{~cm}$, \\
\hline & 1994 & Redução de $70 \%$ da área basal original através de tratamentos silviculturais. \\
\hline T5 & 1985 & $\begin{array}{l}\begin{array}{l}\text { Exploração de } 25 \% \text { do volume total das árvores de DAP > } 60 \mathrm{~cm} \text {, sem redução da área basal após a } \\
\text { exploração. }\end{array}\end{array}$ \\
\hline \multirow{2}{*}{ T6 } & 1985 & Exploração de $25 \%$ do volume total das árvores de DAP > $60 \mathrm{~cm}$. \\
\hline & 1994 & Redução de $30 \%$ da área basal original através de tratamentos silviculturais. \\
\hline \multirow{2}{*}{$\mathrm{T} 7$} & 1985 & Exploração de $25 \%$ do volume total das árvores de DAP > $60 \mathrm{~cm}$. \\
\hline & 1994 & Redução de $50 \%$ da área basal original através de tratamentos silviculturais. \\
\hline \multirow{2}{*}{$\mathrm{T} 8$} & 1985 & Exploração de $25 \%$ do volume total das árvores de DAP > $60 \mathrm{~cm}$. \\
\hline & 1994 & Redução de $70 \%$ da área basal original através de tratamentos silviculturais. \\
\hline T9 & 1985 & $\begin{array}{l}\begin{array}{l}\text { Exploração de } 35 \% \text { do volume total das árvores de DAP > } 60 \mathrm{~cm} \text {, sem redução da área basal após a } \\
\text { exploração. }\end{array} \\
\end{array}$ \\
\hline \multirow{2}{*}{$\mathrm{T} 10$} & 1985 & Exploração de 35\% do volume total das árvores de DAP > $60 \mathrm{~cm}$. \\
\hline & 1994 & Redução de $30 \%$ da área basal original através de tratamentos silviculturais. \\
\hline \multirow{2}{*}{$\mathrm{T} 11$} & 1985 & Exploração de $35 \%$ do volume total das árvores de DAP > $60 \mathrm{~cm}$. \\
\hline & 1994 & Redução de $50 \%$ da área basal original através de tratamentos silviculturais. \\
\hline \multirow{2}{*}{$\mathrm{T} 12$} & 1985 & Exploração de $35 \%$ do volume total das árvores de DAP > $60 \mathrm{~cm}$. \\
\hline & 1994 & Redução de $70 \%$ da área basal original através de tratamentos silviculturais. \\
\hline
\end{tabular}

Fonte: Autores.

\section{Floresta do Moju}

Essa área está localizada no município de Moju, no estado do Pará, com uma área total de 1.050 há de floresta, situado

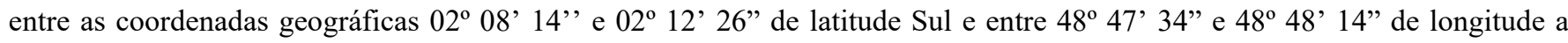
Oeste de Greenwich, entre o km 30 da Rodovia PA-150 e o Rio Ubá. O clima da região é do tipo Am, segundo a classificação de Köppen. A precipitação pluviométrica anual varia de 2.000 a $3.000 \mathrm{~mm}$, distribuída irregularmente, tendo pequenos períodos secos, sendo o período mais chuvoso entre os meses de fevereiro e abril, e o mais seco de agosto a outubro. A umidade relativa do ar em torno de $85 \%$. A temperatura média anual é de $26^{\circ} \mathrm{C}$, o relevo da área experimental é plano, com pequenas ondulações, com declives de até 3\%. Predomina na área o Latossolo Amarelo distrófico com diferentes texturas ocorrendo também solos Podzólicos Vermelhos-amarelos, Glei pouco úmido e plinto solo. A tipologia florestal da área 
experimental é Floresta Ombrófila Densa de terra firme. Possui árvores com o porte variando entre 25 a $35 \mathrm{~m}$ de altura com presença de algumas palmeiras no sub-bosque (Lopes et al., 2001; Silva et al., 2001).

O experimento foi iniciado em $1995 \mathrm{em} 200$ ha de floresta monitorada através do censo florestal. Em 1997, foi realizada a exploração florestal de impacto reduzido. Foram extraídas em média 3,3 árvores.ha ${ }^{-1}$, correspondendo a um volume de 23 $\mathrm{m}^{3} \cdot \mathrm{ha}^{-1}$, que representou $69 \%$ do volume planejado, $33,5 \mathrm{~m}^{3} \cdot \mathrm{ha}^{-1}$, com um total de 31 espécies exploradas com diâmetro mínimo de corte (DMC) de 65 cm. Foram realizados inventários florestais nos anos de 1998, 2010 e 2015. Nesta área não houve tratamentos silviculturais após exploração.

\section{PETECO na fazenda Rio capim}

A área está localizada na fazenda Rio Capim ( $3^{\circ} 30^{\prime}$ e $3^{\circ} 45^{\prime}$ de latitude Sul e $48^{\circ} 30^{\prime}$ e $48^{\circ} 45^{\prime}$ de longitude Oeste), de propriedade da empresa Cikel Brasil Verde Madeiras Ltda., no município de Paragominas, no estado do Pará. A tipologia florestal é Floresta Ombrófila Densa. O clima é Aw, a temperatura é em torno de $27,2{ }^{\circ} \mathrm{C}$, a topografia é plano levemente ondulado e o tipo de solo predominante é o Latossolo amarelo.

Foram estabelecidas de forma aleatória, 36 parcelas permanentes de 0,25 ha em 108 ha, divididos em três tratamentos (Tabela 3), composto por 12 parcelas cada, totalizando uma área amostral de 9 ha. (Francez, 2006).

A exploração foi realizada uniformemente, com exceção da área testemunha, conforme as diretrizes estabelecidas no plano de manejo da empresa. Foram extraídas em média 4,0 árvores.ha ${ }^{-1}$ de 16 espécies comerciais, o equivalente a 17, 8 $\mathrm{m}^{3} / \mathrm{ha}^{-1}$. Foram realizadas seis medições, em 2003, antes da exploração florestal, que foi realizada no mesmo ano, e em 2004, 2005, 2007, 2008 e 2011.

Tabela 3. Tratamentos utilizados no PETECO na fazenda Rio capim.

\begin{tabular}{ll}
\hline Tratamentos Silvicultural & Descrição dos tratamentos silviculturais \\
\hline T0 & Controle, representado pela floresta sem nenhuma intervenção. \\
T1 & Exploração de impacto reduzido com retirada apenas dos fustes das árvores comerciais. \\
T2 & Exploração de impacto reduzido com retirada dos fustes das árvores comerciais, mais a retirada dos \\
& resíduos lenhosos. \\
\hline
\end{tabular}

Fonte: Autores.

\subsection{Coleta dos dados}

Na Tabela 4 são mostrados os períodos de monitoramento de cada área experimental.

Tabela 4. Áreas monitoradas e seus respectivos anos de inventário florestal.

\begin{tabular}{cccccccc}
\hline $\begin{array}{c}\text { Tempo antes e depois } \\
\text { da } \\
\text { Colheita e }\end{array}$ & $\begin{array}{c}\text { Flona do } \\
\text { Tapajós } \\
\text { Ano }\end{array}$ & $\begin{array}{c}\text { Tempo antes e } \\
\text { depois da } \\
\text { Colheita e }\end{array}$ & Jari & $\begin{array}{c}\text { Tempo } \\
\text { antes e } \\
\text { Tratamentos }\end{array}$ & $\begin{array}{c}\text { Moju da } \\
\text { Colheita }\end{array}$ & $\begin{array}{c}\text { Tempo antes e } \\
\text { depois da } \\
\text { Colheita e }\end{array}$ & Peteco \\
Tratamentos & \\
\hline 1 AE & 1981 & $1 \mathrm{AE}$ & 1984 & $2 \mathrm{AE}$ & 1995 & $\mathrm{AE}$ & 2003 \\
1 DE & 1983 & $1 \mathrm{DE}$ & 1986 & $1 \mathrm{DE}$ & 1998 & $1 \mathrm{DE}$ & 2004 \\
$5 \mathrm{DE}$ & 1987 & $3 \mathrm{DE}$ & 1988 & $13 \mathrm{DE}$ & 2010 & $2 \mathrm{DE}$ & 2005 \\
$7 \mathrm{DE}$ & 1989 & $5 \mathrm{DE}$ & 1990 & $18 \mathrm{DE}$ & 2015 & $4 \mathrm{DE}$ & 2007 \\
13 DE/1DT & 1995 & $9 \mathrm{DE}$ & 1994 & & & $5 \mathrm{DE}$ & 2008 \\
26DE/14DT/11DF & 2008 & 11DE/2DT & 1996 & & & $8 \mathrm{DE}$ & 2011 \\
30DE/18DT/15DF & 2012 & 19DE10AT & 2004 & & & & \\
\hline
\end{tabular}

AE: Antes da exploração; DE Depois da exploração; AT; Antes dos tratamentos Silviculturais, DT: Depois dos tratamentos Silviculturais, DF: Depois do fogo acidental. Fonte: Autores. 


\section{Análise dos dados}

\section{Análise de variância}

Inicialmente foram avaliadas as suposições para utilização da Anova ao nível de significância de 0,05 para todos os testes. A hipótese de homogeneidade das variâncias foi avaliada pelo teste de Levene e para a comparação de médias foi usado o Teste F e de Welch. Foram realizados o teste de Tukey e o teste de Games Howell, para o caso de variâncias desiguais.

Para a floresta nacional do Tapajós para o tratamento T0 do ano de 1981 foi utilizado a formula Banzatto e Kronka 2006, para a estimativa da parcela perdida:

$$
\mathrm{X} i j=\frac{I T+J B-G^{n}}{(I-1)(J-1)}
$$

Onde: I=Número de tratamentos

$\mathrm{T}=$ Soma das parcelas do tratamento com a parcela perdida

$\mathrm{J}=$ Número de blocos

$\mathrm{B}=$ Soma das parcelas do bloco com a parcela perdida

$\mathrm{G}^{`}=$ Soma das parcelas existentes.

Para o pequeno tamanho das amostras em cada tratamento da área do Jari, foi realizada a comparação de médias utilizando técnica não-paramétrica, a Anova de Kruskall-Wallis.

\section{Riqueza de espécies}

Foi considerado o número de espécies nos tratamentos por ano, não teve cálculo.

\section{Índice equabilidade de Pielou $\mathbf{J}$ '}

Este índice se refere ao quanto de similaridade as espécies estão representadas na comunidade, caso todas as espécies tenham a mesma representatividade na comunidade a sua equabilidade será máxima e igual a 1 ou $100 \%$. A razão entre a diversidade observada(H') e a diversidade máxima(H'max) são utilizadas para medir a uniformidade ou equabilidade de Pielou (J '), que é derivada do índice de diversidade de Shannon e permite representar a uniformidade de distribuição de indivíduos entre espécies existentes (PIELOU, 1969) de acordo com a equação:

$$
I^{\prime}=H^{\prime} / H^{\prime}{ }_{\max }=H^{\prime} / \ln S \text {. }
$$

Onde: $\mathrm{H}^{\prime}=$ índice de diversidade de Shannon-Wiener; H'max = índice máximo de diversidade.

\section{Índice de diversidade de Shannon-Wiener}

Os índices de diversidade combinam a riqueza e a equabilidade de uma comunidade. O índice de Shannon-Wiener é muito sensível ao tamanho da amostra, sendo um ponto de referência para medir a diversidade biológica (MARGURAN, 2011). O índice de Shannon foi calculado pela equação:

$$
H^{\prime}=\frac{N \cdot \ln (N)-\sum_{i=1}^{S} n_{i} \cdot \ln \left(n_{i}\right)}{N}
$$

Onde: $\mathrm{ni}=$ número de indivíduos amostrados da espécie $\mathrm{i} ; \mathrm{N}=$ número total de indivíduos amostrados; $\mathrm{S}=$ número total de espécies amostradas; $\ln =$ logaritmo neperiano. 
A máxima diversidade possível (H'max) é observada em uma situação em que todas as espécies tiveram abundância igual, de acordo com a equação:

$$
H_{\max }^{\prime}=\ln S
$$

Onde: $\mathrm{S}$ = número total de espécies amostradas; $\ln$ = logaritmo neperiano

A diversidade de uma comunidade é máxima se $\mathrm{S}=\mathrm{N}$ ou se a relação $\mathrm{N} / \mathrm{S}$ é aproximadamente constante.

\section{Índice de Simpson}

O índice de diversidade de Simpson foi usado para calcular a probabilidade de que quaisquer dois indivíduos sorteados aleatoriamente de uma comunidade infinitamente grande pertençam à mesma espécie. Este índice nos dá uma boa estimativa da diversidade em tamanhos populacionais razoavelmente pequenos, e também ordena espécies consistentemente mesmo quando as curvas de acumulação de espécies se cruzam (MARGURAN, 2011) de acordo com a equação:

$$
D=\sum p i^{2}
$$

Onde: $\mathrm{D}$ = índice de dominância de Simpson; pi = proporção de indivíduos na espécie i, que indica a probabilidade de dois indivíduos retirados ao acaso pertencerem a espécies diferentes(Melo,2008).

O índice de Simpson é geralmente representado por 1-D ou 1 / D, que é uma das medidas de diversidade mais significativas. Ele captura a variação da distribuição de abundância de espécies. Quando expresso como (1-D) ou recíproco (1 / D) de D, o valor da medição aumentará à medida que a amostragem se tornar mais uniforme. D é dominância e 1-D é igual a diversidade e ambos são inversamente proporcionais.

\section{Índice de similaridade/dissimilaridade de Bray-Curts}

Quando queremos comparar amostras não só pelas presenças, mas também por suas abundâncias precisamos usar um índice quantitativo. Para saber até que ponto as populações se distanciaram ou diferiram ao longo do tempo, foi utilizado o índice de similaridade/dissimilaridade de Bray-Curtis, que varia entre zero e um, onde quando o valor obtido for igual a um, indica que as duas amostras são idênticas e quando o valor obtido for igual a zero, indica que as amostras não têm nenhuma espécie em comum, o índice reflete diferenças na abundancia total.

A similaridade de Bray-Curtis é calculada pela seguinte formula:

$$
C_{N}=\frac{2 \mathrm{JN}}{(\mathrm{Na}+\mathrm{Nb})}
$$

Onde $\mathrm{N}_{\mathrm{a}}$ é o número total de indivíduos no ano $\mathrm{A} ; \mathrm{N}_{\mathrm{b}}$ é o número total de indivíduos no ano $\mathrm{B}$; e $2 \mathrm{jN} \_$é a soma da mais baixa das duas abundancias para espécies encontradas nos dois anos.

\section{Resultados e Discussão}

\section{Analise de variância}

Flona do Tapajós

A Tabela 5 apresenta o número médio de espécie em cada tratamento por ano e é realizada a comparação entre os tratamentos. Os resultados evidenciaram que apenas em 1981, antes da exploração, não foi constatada diferença estatística no número médio de espécies entre os tratamentos ao nível de significância de 5\%. Nos anos seguintes, foi constatada a diferença entre os tratamentos. Nos anos de 1983 e 1987 foram identificadas diferenças estatísticas entre os tratamentos T0 e T1, T0 e 
T3, T1 e T2, T2 e T3. No ano de 1989 só apresentou diferença entre os tratamentos T0 e T3. Em 1995 e 2008 ficou evidenciado que o tratamento T3 diferia de T0, T1 e T2. Em 2008 T3 mostrou-se estatisticamente diferente apenas de T0.

Tabela 5. Comparação do número médio de espécies entre os tratamentos por ano na Flona do Tapajós.

\begin{tabular}{ccccccccc}
\hline & \multicolumn{9}{c}{ Número médio de espécies } & F & Teste Tukey \\
\hline & Ano & T0 & T1 & T2 & T3 & T4 & p valor \\
1 AE & 1981 & 53,58 & 48,00 & 49,00 & 45,83 & 50,00 & 0,175 \\
$1 \mathrm{DE}$ & 1983 & 49,08 & 39,92 & 50,92 & 39,58 & 51,58 & $0,001^{*}$ \\
5 DE & 1987 & 52,08 & 42,33 & 53,58 & 41,67 & 50,67 & $0,001^{*}$ \\
7 DE & 1989 & 54,25 & 48,83 & 53,17 & 44,67 & 53,17 & $0,011^{*}$ \\
13 DE/1DT & 1995 & 52,58 & 53,67 & 54,67 & 37,50 & 50,42 & $0,000^{*}$ \\
26DE/14DT/11DF & 2008 & 57,67 & 57,08 & 60,83 & 41,83 & 65,42 & $0,000^{*}$ \\
30DE/18DT/15DF & 2012 & 56.08 & 51.83 & 53.50 & 44.67 & 50.92 & $0,039^{*}$ \\
\hline
\end{tabular}

*diferença estatística a 5\% de significância. Fonte: Autores.

\section{Companhia Florestal Monte Dourado- Jari}

A Tabela 6 apresenta as médias anuais por tratamento e o p valor do teste. Observa-se que há diferença estatística apenas nos anos de 1988, 1996 e 2004, entretanto é importante ressaltar que apenas no ano de 1984 o teste oferece uma comprovação expressiva que não existe diferença entre os tratamentos.

Tabela 6. Comparação do número médio de espécies entre os tratamentos por ano na Companhia Florestal Monte DouradoJari.

\begin{tabular}{|c|c|c|c|c|c|c|c|c|c|c|c|c|c|c|c|}
\hline Ano & Evento & & & & & & Númer & médio de & espécies & & & & & & K-S \\
\hline & Evento & T0 & T1 & $\mathrm{T} 2$ & T3 & T4 & T5 & T6 & $\mathrm{T} 7$ & T8 & T9 & T10 & T11 & T12 & P-valor \\
\hline 1984 & $1 \mathrm{AE}$ & 195,00 & 186,67 & 185,33 & 170,00 & 185,00 & 173,33 & 165,67 & 175,00 & 174,67 & 179,33 & 164,67 & 172,00 & 174,67 & 0,215 \\
\hline 1986 & $1 \mathrm{DE}$ & 199,50 & 179,67 & 178,33 & 168,00 & 184,67 & 164,00 & 157,33 & 161,33 & 161,00 & 169,00 & 147,67 & 158,33 & 163,67 & 0,070 \\
\hline 1988 & $3 \mathrm{DE}$ & 197,50 & 175,67 & 178,00 & 168,00 & 180,33 & 158,33 & 158,00 & 158,33 & 156,33 & 164,00 & 143,67 & 154,33 & 162,00 & $0,037 *$ \\
\hline 1990 & $5 \mathrm{DE}$ & 191,25 & 168,00 & 175,67 & 168,67 & 176,00 & 154,33 & 157,33 & 155,33 & 158,00 & 164,67 & 146,00 & 146,33 & 162,33 & 0,053 \\
\hline 1994 & $9 \mathrm{DE}$ & 197,25 & 176,00 & 176,67 & 175,67 & 180,33 & 166,33 & 165,67 & 163,00 & 165,00 & 176,33 & 157,33 & 159,67 & 170,00 & 0,102 \\
\hline 1996 & $11 \mathrm{DE} / 2 \mathrm{DT}$ & 198,00 & 177,00 & 171,00 & 151,33 & 172,67 & 168,00 & 158,00 & 144,00 & 164,00 & 181,00 & 162,33 & 133,00 & 172,33 & $0,010 *$ \\
\hline 2004 & 19DE10AT & 196,50 & 190,33 & 184,33 & 160,33 & 184,00 & 188,00 & 164,00 & 149,33 & 180,67 & 196,33 & 181,33 & 155,00 & 200,67 & $0,030 *$ \\
\hline 2011 & 26DE/17AT & 201,00 & 188,67 & 182,33 & 149,67 & 191,00 & 186,00 & 168,67 & 159,67 & 195,67 & 197,67 & 195,33 & 171,67 & 188,00 & 0,109 \\
\hline
\end{tabular}

Fonte: Autores.

\section{Floresta do Moju}

Devido à ausência de tratamentos foi realizada somente a Anova para medidas repetidas, buscando evidenciar diferenças ao longo do tempo (Tabela 7). O resultado apontado relata a existência de diferenças na diversidade média de espécies entre os anos estudados. Os testes para as comparações pareadas constataram a não existência de diferença na diversidade média nos anos de 1998 e 1995 e entre os anos 2010 e 2015, formando dois grupos homogêneos.

Tabela 7. Comparação do número médio de espécies entre os anos na área experimental da floresta do Moju.

\begin{tabular}{ccccc}
\hline Evento & Ano & Média & F & Tukey \\
\hline $\mathbf{2}$ AE & 1998 & 93,27 & P valor $=0,000$ & \\
1DE & 1995 & 92,64 & & \\
$\mathbf{1 3 D E}$ & 2010 & 105,32 & & \\
$\mathbf{1 8 D E}$ & 2015 & 108,45 & & \\
\hline
\end{tabular}




\section{PETECO na fazenda Rio capim}

Para riqueza de espécies da área do Peteco, a Anova não evidenciou diferenças estatisticamente significativas entre os tratamentos em cada ano (Tabela 8).

Tabela 8. Comparação entre os tratamentos por ano na área do PETECO na fazenda Rio capim.

\begin{tabular}{|c|c|c|c|c|c|c|}
\hline \multirow[b]{2}{*}{ Evento } & \multirow[b]{2}{*}{ Ano } & \multicolumn{3}{|c|}{ Média das espécies } & \multirow{2}{*}{$\frac{F}{p \text { valor }}$} & \multirow[t]{2}{*}{ Tukey } \\
\hline & & T0 & $\mathrm{T} 1$ & $\mathrm{~T} 2$ & & \\
\hline $\mathrm{AE}$ & 2003 & 44,58 & 45,67 & 46,75 & 0,604 & \\
\hline $1 \mathrm{DE}$ & 2004 & 44,75 & 43,50 & 45,00 & 0,750 & \\
\hline $2 \mathrm{DE}$ & 2005 & 43,50 & 43,17 & 45,50 & 0,536 & \\
\hline $4 \mathrm{DE}$ & 2007 & 44,00 & 43,42 & 46,92 & 0,265 & \\
\hline $5 \mathrm{DE}$ & 2008 & 44,75 & 43,50 & 46,58 & 0,374 & \\
\hline $8 \mathrm{DE}$ & 2011 & 45,42 & 45,75 & 47,08 & 0,788 & \\
\hline
\end{tabular}

Fonte: Autores.

\section{Riqueza, equabilidade e diversidade florística}

\section{Flona do Tapajós}

Quanto a riqueza de espécies absoluta verificou-se que cada tratamento antes da exploração já tinham um número especifico de espécie T1=148, T2=156, T3=135 e T4=154, um ano após a exploração de impacto reduzido, houve uma diminuição no número de espécies para os tratamentos em que houve exploração, T1 menos 9, T2 menos 7, T3 menos 9 e T4 menos 9 espécies o tratamento T0 começou a ser observado neste ano e o mesmo tinha 105 espécies. Porém no decorrer das observações foi observado que o número de espécies também recupera muito mais rápido em menos tempo comparado com a floresta sem exploração.

A equabilidade durante este mesmo período para os tratamentos que tiveram exploração, houve um aumento no índice do tratamento $\mathrm{T} 1=0,86$ para $0,87, \mathrm{~T} 2, \mathrm{~T} 3$ continuaram com o mesmo índice de antes da colheita 0,86 e 0,85 respectivamente e o tratamento T4 teve uma diminuição nesse índice de 0,87 para 0,82. O índice de Shanon para esse período teve uma diminuição para todos os tratamentos em que houve exploração T1, T2, T3 e T4 (Tabela 9). O índice de Simpson continuou o mesmo para os tratamentos T1 e T3 com o valor de 0,97 e teve uma diminuição para os tratamentos T2 de 0,98 para 0,97 e T4 de0,98 pra 0,96.

Um ano após o desbaste em três tratamentos T2, T3 e T4 teve uma nova medição, a qual observou-se que o tratamento T2 estava com 6 espécies a menos, o T3 com quatro a menos e o T4 com 5 espécies a mais, sendo que a medição de referência foi cinco anos antes do desbaste. A Equabilidade para este período e tratamento silvicultural continuou a mesma para o tratamento T2 em 0,87 e teve variação para menos no T3 de 0,88 para 0,89 e para mais no T4 de 0,86 para 0,88. Quanto ao índice de Shanon e de Simpson no tratamento T2 continuou com os mesmos valores 4,44 e 0,98 respectivamente. No tratamento T3 o índice de Shanon diminuiu de 4,29 para 4,19 e o de Simpson aumentou de 0,97 para 0,98. No tratamento T4os dois índices tiveram aumento o de Shanon de 4,31 para 4,4 e o de Simpson de 0,97 para 0,98.

Onze anos após o fogo, podemos constatar que o tratamento T0 estava com seis espécies a mais do que antes do fogo e o tratamento T4 que também teve o mesmo número de parcelas incendiadas, estava com 35 espécies a mais. O tratamento T1 estava com quatro espécies a menos, o T2 com 16 a mais e o T3 com seis espécies a mais, sendo que, somente este tratamento não teve parcelas queimadas. A Equabilidade neste período para os tratamentos ficou igual para o tratamento T0 com 0,88 e teve um aumento no índice de Shanon de 4,07 para 4,11e ficou com o mesmo valor no índice de Simpson de 0,97.para o tratamento T1a Equabilidade aumentou, o índice de Simpson aumentou e o índice de Shanon ficou o mesmo, já o tratamento T2 a equabilidade 
ficou a mesma, o índice de Shanon aumentou e o índice de Simpson ficou o mesmo, para o tratamento T3 que não teve fogo Equabilidade continuou a mesma, o índice de Shanon aumentou e o índice de Simpson continuou o mesmo, para o tratamento T4 a Equabilidade diminuiu, o índice de Shanon aumentou e o índice de Simpson diminuiu.

No final das observações 30 anos após a exploração de impacto reduzido, podemos constatar que o tratamento T0 que começou a ser medido após a exploração, porém teve metade de suas parcelas incendiadas, teve um número de espécies superior em uma unidade. $\mathrm{O}$ tratamento $\mathrm{T} 1$ que foi explorado e teve duas parcelas com fogo, teve um número de espécies superior em 5 unidades, o tratamento T2 que teve exploração, tratamentos silviculturais e fogo em cinco parcelas, teve um número de espécies superior em 13 unidades, o tratamento T3 que teve exploração e tratamentos silviculturais, teve um número de espécies inferior em 1 unidade e o tratamento T4 que teve exploração, tratamentos silviculturais e fogo em metade de suas parcelas teve um número de espécies superior em 26 unidades.

A equabilidade diminuiu para os tratamentos T0 e T4, nos outros ouve um aumento, o índice de Shanon diminuiu para o $\mathrm{T} 0$ enquanto todos os outros tratamentos tiveram aumento. O índice de Simpson manteve-se constante no tratamento T0 e T2, teve um aumento nos tratamentos T1 e T3, e diminuiu no tratamento T4.

Tabela 9. Demonstração da Riqueza (S), Índice de Shannon (H’), Índice máximo de Shanon (H’max), Equabilidade de Pielou (J'), Índice de dominância de Simpson(D) e Índice diversidade Simpson (1-D) por ano e tratamento silvicultural na Floresta nacional do Tapajós, Belterra, Pará.

\begin{tabular}{|c|c|c|c|c|}
\hline \multicolumn{5}{|c|}{ Tratamento T0 } \\
\hline Ano $\mathrm{C} / \mathrm{T} / \mathrm{F}$ & $\mathrm{S}$ & $\mathrm{J}$ & $\mathrm{H}^{-}$ & 1-D \\
\hline $1 \mathrm{DE}$ & 105 & 0,89 & 4,14 & 0,97 \\
\hline $5 \mathrm{DE}$ & 104 & 0,88 & 4,1 & 0,97 \\
\hline $7 \mathrm{DE}$ & 100 & 0,88 & 4,07 & 0,97 \\
\hline $13 \mathrm{DE} / 1 \mathrm{DT}$ & 102 & 0,88 & 4,07 & 0,97 \\
\hline $26 \mathrm{DE} / 14 \mathrm{DT} / 11 \mathrm{DF}$ & 108 & 0,88 & 4,11 & 0,97 \\
\hline 30DE/18DT/15 DF & 106 & 0,87 & 4,07 & 0,97 \\
\hline \multicolumn{5}{|c|}{ Tratamento $\mathrm{T} 1$} \\
\hline Ano $\mathrm{C} / \mathrm{T} / \mathrm{F}$ & $\mathrm{S}$ & $\mathrm{J}$ & $\mathrm{H}^{\prime}$ & $1-\mathrm{D}$ \\
\hline $1 \mathrm{AE}$ & 148 & 0,86 & 4,29 & 0,97 \\
\hline $1 \mathrm{DE}$ & 134 & 0,87 & 4,28 & 0,97 \\
\hline $5 \mathrm{DE}$ & 135 & 0,88 & 4,3 & 0,97 \\
\hline $7 \mathrm{DE}$ & 154 & 0,86 & 4,35 & 0,98 \\
\hline $13 \mathrm{DE} / 1 \mathrm{DT}$ & 155 & 0,84 & 4,24 & 0,97 \\
\hline $26 \mathrm{DE} / 14 \mathrm{DT} / 11 \mathrm{DF}$ & 151 & 0,85 & 4,25 & 0,97 \\
\hline $30 \mathrm{DE} / 18 \mathrm{DT} / 15 \mathrm{DF}$ & 153 & 0,87 & 4,37 & 0,98 \\
\hline \multicolumn{5}{|c|}{ Tratamento T2 } \\
\hline Ano $C / T / F$ & $\mathrm{~S}$ & $\mathrm{~J}$ & $\mathrm{H}^{\prime}$ & 1-D \\
\hline $1 \mathrm{AE}$ & 156 & 0,86 & 4,35 & 0,98 \\
\hline $1 \mathrm{DE}$ & 149 & 0,86 & 4,28 & 0,97 \\
\hline $5 \mathrm{DE}$ & 170 & 0,87 & 4,47 & 0,98 \\
\hline $7 \mathrm{DE}$ & 166 & 0,87 & 4,44 & 0,98 \\
\hline $13 \mathrm{DE} / 1 \mathrm{DT}$ & 160 & 0,87 & 4,44 & 0,98 \\
\hline $26 \mathrm{DE} / 14 \mathrm{DT} / 11 \mathrm{DF}$ & 176 & 0,87 & 4,52 & 0,98 \\
\hline $30 \mathrm{DE} / 18 \mathrm{DT} / 15 \mathrm{DF}$ & 169 & 0,88 & 4,51 & 0,98 \\
\hline \multicolumn{5}{|c|}{ Tratamento T3 } \\
\hline Ano $\mathrm{C} / \mathrm{T}$ & $\mathrm{S}$ & $\mathrm{J}$ & $\mathrm{H}^{\prime}$ & 1-D \\
\hline $1 \mathrm{AE}$ & 135 & 0,85 & 4,16 & 0,97 \\
\hline $1 \mathrm{DE}$ & 126 & 0,85 & 4,12 & 0,97 \\
\hline $5 \mathrm{DE}$ & 126 & 0,85 & 4,13 & 0,97 \\
\hline $7 \mathrm{DE}$ & 128 & 0,88 & 4,29 & 0,97 \\
\hline $13 \mathrm{DE} / 1 \mathrm{DT}$ & 124 & 0,87 & 4,19 & 0,98 \\
\hline $26 \mathrm{DE} / 14 \mathrm{DT} / 11 \mathrm{DF}$ & 130 & 0,87 & 4,26 & 0,98 \\
\hline 30DE/18DT/15 DF & 134 & 0,87 & 4,26 & 0,98 \\
\hline
\end{tabular}




\begin{tabular}{ccccc}
\hline & \multicolumn{5}{c}{ Tratamento T4 } \\
\hline Ano C/ T & $\mathrm{S}$ & $\mathrm{J}$ & $\mathrm{H}^{\prime}$ & $1-\mathrm{D}$ \\
$1 \mathrm{AE}$ & 154 & 0,87 & 4,38 & 0,98 \\
$1 \mathrm{DE}$ & 145 & 0,82 & 4,1 & 0,96 \\
$5 \mathrm{DE}$ & 153 & 0,85 & 4,25 & 0,97 \\
$7 \mathrm{DE}$ & 147 & 0,86 & 4,31 & 0,97 \\
$13 \mathrm{DE} / 1 \mathrm{DT}$ & 152 & 0,88 & 4,4 & 0,98 \\
$26 \mathrm{DE} / 14 \mathrm{DT} / 11 \mathrm{DF}$ & 187 & 0,85 & 4,44 & 0,97 \\
$30 \mathrm{DE} / 18 \mathrm{DT} / 15 \mathrm{DF}$ & 170 & 0,86 & 4,41 & 0,97 \\
\hline
\end{tabular}

Fonte: Autores.

\section{Companhia Florestal Monte Dourado- Jari}

Quanto à riqueza de espécies absoluta verificou-se que cada tratamento antes da exploração já tinham um número específico de espécie $\mathrm{T} 0=182, \mathrm{~T} 1=148, \mathrm{~T} 2=157, \mathrm{~T} 3=130, \mathrm{~T} 4=164, \mathrm{~T} 5=154, \mathrm{~T} 6=148, \mathrm{~T} 7=152, \mathrm{~T} 8=142, \mathrm{~T} 9=157, \mathrm{~T} 10=139$, T11=137 e T12=136, um ano após a exploração de impacto reduzido, houve uma diminuição no número de espécies para a maior parte dos tratamentos, somente o tratamento T0 e o T3 aumentou uma unidade, e o T1 e o T7 continuaram com o mesmo número de espécies. A Equabilidade após a exploração aumentou para os tratamentos T1, T8 e T11, os outros tratamentos ficaram com o mesmo valor, quanto ao índice de Shanon o mesmo aumentou para os tratamentos T0, T1, T3, T5, T7 e T12, diminuiu para os tratamentos T6, T8, T9e T10, os outros tratamentos ficaram com o mesmo valor de antes da exploração (Tabela10).

Nove anos após a exploração constatou-se que somente os tratamentos T4 e T5, não haviam recuperado o número de espécies que tinham antes da colheita. A Equabilidade durante este mesmo período aumentou para os tratamentos T1, T6, T7 e T8. O índice de diversidade de Shanon aumentou para todos os tratamentos com exceção para o T5 que continuou com o mesmo valor de antes da exploração. O índice de diversidade de Simpson aumentou para os tratamentos T1, T7 e T8.

Dois anos após o desbaste em oito tratamentos T2, T3, T4, T6, T7, T8, T10, T11, T12, houve uma nova medição, a qual foi observado que os tratamentos T10 e T12 foram os únicos que não tiveram perda no número de espécies. A Equabilidade para este período aumentou para os tratamentos T2 e T4 e diminuiu para os tratamentos T3, T7, T10 e T11. Quanto ao índice de Shanon ele permaneceu o mesmo para os tratamentos T0 e T2 e aumentou nos tratamentos T1, T4, T9 e T12. O índice de Simpson Diminuiu nos tratamentos T3 e T7.

Vinte e seis anos após a exploração e dezessete anos após os tratamentos silviculturais somente o tratamento T3 não recuperou o número de espécies que tinha antes da exploração florestal. Quando a Equabilidade os tratamentos T3, T5, T7 continuaram com mesmo valor, o tratamento T10 teve uma leve diminuição e os outros tratamentos todos ficaram com o índice superior que o de antes da exploração.

Tabela 10. Riqueza (S), Índice de Shannon (H'), Índice máximo de Shanon (H'max), equabilidade(J'), Índice de dominância de Simpson(D) e Índice diversidade Simpson(1-D) na área experimental da Jari.

\begin{tabular}{ccccc}
\hline & \multicolumn{3}{c}{ Tratamento T0 } \\
\hline Ano C/T & S & J' & H' & $1-\mathrm{D}$ \\
$\mathbf{1 A E}$ & 182 & 0,88 & 4,59 & 0,98 \\
$\mathbf{1 D E}$ & 183 & 0,88 & 4,60 & 0,98 \\
$\mathbf{3}$ DE & 185 & 0,88 & 4,61 & 0,98 \\
$\mathbf{5}$ DE & 186 & 0,88 & 4,60 & 0,98 \\
$\mathbf{9}$ DE & 190 & 0,88 & 4,62 & 0,98 \\
$\mathbf{1 1}$ DE/2DT & 188 & 0,88 & 4,62 & 0,98 \\
$\mathbf{1 9}$ DE/10AT & 200 & 0,89 & 4,72 & 0,98 \\
26 DE/17AT & 206 & 0,89 & 4,76 & \\
\hline
\end{tabular}


Research, Society and Development, v. 10, n. 13, e431101315484, 2021

(CC BY 4.0) | ISSN 2525-3409 | DOI: http://dx.doi.org/10.33448/rsd-v10i13.15484

\begin{tabular}{|c|c|c|c|c|}
\hline \multicolumn{5}{|c|}{ Tratamento T1 } \\
\hline Ano C/T & $\mathrm{S}$ & J' & $\mathrm{H}^{\prime}$ & 1-D \\
\hline 1AE & 148 & 0,90 & 4,50 & 0,98 \\
\hline 1DE & 148 & 0,91 & 4,52 & 0,98 \\
\hline 3 DE & 144 & 0,91 & 4,51 & 0,98 \\
\hline $5 \mathrm{DE}$ & 146 & 0,91 & 4,54 & 0,98 \\
\hline 9 DE & 156 & 0,91 & 4,61 & 0,99 \\
\hline $11 \mathrm{DE} / 2 \mathrm{DT}$ & 160 & 0,91 & 4,64 & 0,99 \\
\hline $19 \mathrm{DE} / 10 \mathrm{AT}$ & 179 & 0,91 & 4,72 & 0,99 \\
\hline 26 DE/17AT & 184 & 0,91 & 4,75 & 0,99 \\
\hline \multicolumn{5}{|c|}{ Tratamento T2 } \\
\hline Ano C/T & $S$ & J' & $\mathrm{H}^{\prime}$ & 1-D \\
\hline 1AE & 157 & 0,88 & 4,46 & 0,98 \\
\hline 1DE & 155 & 0,88 & 4,46 & 0,98 \\
\hline 3 DE & 158 & 0,88 & 4,48 & 0,98 \\
\hline $5 \mathrm{DE}$ & 157 & 0,88 & 4,46 & 0,98 \\
\hline 9 DE & 158 & 0,88 & 4,47 & 0,98 \\
\hline $11 \mathrm{DE} / 2 \mathrm{DT}$ & 155 & 0,89 & 4,47 & 0,98 \\
\hline $19 \mathrm{DE} / 10 \mathrm{AT}$ & 169 & 0,89 & 4,58 & 0,98 \\
\hline $26 \mathrm{DE} / 17 \mathrm{AT}$ & 169 & 0,89 & 4,57 & 0,98 \\
\hline \multicolumn{5}{|c|}{$\frac{0,09}{\text { Tratamento T3 }}$} \\
\hline Ano C/T & $S$ & J' & $\mathrm{H}^{\prime}$ & 1-D \\
\hline 1AE & 130 & 0,89 & 4,32 & 0,98 \\
\hline 1DE & 131 & 0,89 & 4,34 & 0,98 \\
\hline 3 DE & 131 & 0,89 & 4,34 & 0,98 \\
\hline $5 \mathrm{DE}$ & 131 & 0,89 & 4,35 & 0,98 \\
\hline $9 \mathrm{DE}$ & 134 & 0,89 & 4,35 & 0,98 \\
\hline $11 \mathrm{DE} / 2 \mathrm{DT}$ & 117 & 0,87 & 4,16 & 0,97 \\
\hline $19 \mathrm{DE} / 10 \mathrm{AT}$ & 127 & 0,88 & 4,29 & 0,98 \\
\hline $26 \mathrm{DE} / 17 \mathrm{AT}$ & 128 & 0,89 & 4,32 & 0,98 \\
\hline \multicolumn{5}{|c|}{ Tratamento T4 } \\
\hline Ano C/T & $\mathrm{S}$ & $\mathrm{J}$ & $\overline{\mathrm{H}^{\prime}}$ & 1-D \\
\hline 1AE & 164 & 0,89 & 4,52 & 0,98 \\
\hline $1 D E$ & 163 & 0,89 & 4,52 & 0,98 \\
\hline 3 DE & 164 & 0,89 & 4,55 & 0,98 \\
\hline $5 \mathrm{DE}$ & 161 & 0,89 & 4,53 & 0,98 \\
\hline $9 \mathrm{DE}$ & 163 & 0,89 & 4,55 & 0,98 \\
\hline $11 \mathrm{DE} / 2 \mathrm{DT}$ & 161 & 0,90 & 4,56 & 0,98 \\
\hline $19 \mathrm{DE} / 10 \mathrm{AT}$ & 179 & 0,90 & 4,67 & 0,98 \\
\hline $26 \mathrm{DE} / 17 \mathrm{AT}$ & 178 & 0,90 & 4,66 & 0,98 \\
\hline \multicolumn{5}{|c|}{ Tratamento T5 } \\
\hline Ano C/T & $\mathrm{S}$ & J' & $\overline{\mathrm{H}^{\prime}}$ & 1-D \\
\hline $1 \mathrm{AE}$ & 154 & 0,90 & 4,51 & 0,98 \\
\hline 1DE & 151 & 0,90 & 4,52 & 0,98 \\
\hline $3 \mathrm{DE}$ & 147 & 0,90 & 4,50 & 0,98 \\
\hline $5 \mathrm{DE}$ & 145 & 0,90 & 4,49 & 0,98 \\
\hline $9 \mathrm{DE}$ & 147 & 0,90 & 4,51 & 0,98 \\
\hline $11 \mathrm{DE} / 2 \mathrm{DT}$ & 146 & 0,90 & 4,49 & 0,98 \\
\hline $19 \mathrm{DE} / 10 \mathrm{AT}$ & 168 & 0,90 & 4,59 & 0,98 \\
\hline $26 \mathrm{DE} / 17 \mathrm{AT}$ & 165 & 0,90 & 4,62 & 0,98 \\
\hline \multicolumn{5}{|c|}{ Tratamento T6 } \\
\hline Ano C/T & $\mathrm{S}$ & J' & $\overline{\mathrm{H}^{\prime}}$ & 1-D \\
\hline 1AE & 148 & 0,90 & 4,49 & 0,98 \\
\hline 1DE & 141 & 0,90 & 4,47 & 0,98 \\
\hline 3 DE & 147 & 0,91 & 4,52 & 0,98 \\
\hline $5 \mathrm{DE}$ & 147 & 0,91 & 4,53 & 0,98 \\
\hline $9 \mathrm{DE}$ & 156 & 0,91 & 4,60 & 0,98 \\
\hline $11 \mathrm{DE} / 2 \mathrm{DT}$ & 151 & 0,91 & 4,57 & 0,98 \\
\hline $19 \mathrm{DE} / 10 \mathrm{AT}$ & 159 & 0,91 & 4,62 & 0,98 \\
\hline $26 \mathrm{DE} / 17 \mathrm{AT}$ & 164 & 0,91 & 4,66 & 0,99 \\
\hline \multicolumn{5}{|c|}{ Tratamento T7 } \\
\hline Ano C/T & $\mathrm{S}$ & J' & $\mathrm{H}^{\prime}$ & 1-D \\
\hline 1AE & 152 & 0,91 & 4,55 & 0,98 \\
\hline 1DE & 152 & 0,91 & 4,57 & 0,98 \\
\hline 3 DE & 153 & 0,91 & 4,58 & 0,98 \\
\hline $5 \mathrm{DE}$ & 151 & 0,91 & 4,58 & 0,98 \\
\hline $9 \mathrm{DE}$ & 158 & 0,92 & 4,63 & 0,99 \\
\hline
\end{tabular}


Research, Society and Development, v. 10, n. 13, e431101315484, 2021

(CC BY 4.0) | ISSN 2525-3409 | DOI: http://dx.doi.org/10.33448/rsd-v10i13.15484

\begin{tabular}{|c|c|c|c|c|}
\hline $11 \mathrm{DE} / 2 \mathrm{DT}$ & 145 & 0,91 & 4,51 & 0,98 \\
\hline $19 \mathrm{DE} / 10 \mathrm{AT}$ & 160 & 0,91 & 4,62 & 0,98 \\
\hline $26 \mathrm{DE} / 17 \mathrm{AT}$ & 176 & 0,91 & 4,72 & 0,99 \\
\hline \multicolumn{5}{|c|}{ Tratamento T8 } \\
\hline Ano C/T & $S$ & J' & $\mathrm{H}^{\prime}$ & $1-\mathrm{D}$ \\
\hline $1 \mathrm{AE}$ & 142 & 0,87 & 4,30 & 0,97 \\
\hline 1DE & 133 & 0,88 & 4,28 & 0,97 \\
\hline 3 DE & 133 & 0,87 & 4,28 & 0,97 \\
\hline $5 \mathrm{DE}$ & 142 & 0,88 & 4,36 & 0,97 \\
\hline 9 DE & 151 & 0,88 & 4,42 & 0,98 \\
\hline $11 \mathrm{DE} / 2 \mathrm{DT}$ & 149 & 0,88 & 4,39 & 0,98 \\
\hline $19 \mathrm{DE} / 10 \mathrm{AT}$ & 157 & 0,89 & 4,50 & 0,98 \\
\hline 26 DE/17AT & 169 & 0,90 & 4,60 & 0,98 \\
\hline \multicolumn{5}{|c|}{ Tratamento T9 } \\
\hline Ano C/T & $\mathrm{S}$ & $\mathrm{J} '$ & $\overline{\mathrm{H}^{\prime}}$ & $1-\mathrm{D}$ \\
\hline 1AE & 157 & 0,88 & 4,46 & 0,98 \\
\hline 1DE & 154 & 0,88 & 4,43 & 0,98 \\
\hline 3 DE & 154 & 0,88 & 4,45 & 0,98 \\
\hline $5 \mathrm{DE}$ & 155 & 0,88 & 4,46 & 0,98 \\
\hline 9 DE & 157 & 0,89 & 4,48 & 0,98 \\
\hline $11 \mathrm{DE} / 2 \mathrm{DT}$ & 160 & 0,89 & 4,50 & 0,98 \\
\hline $19 \mathrm{DE} / 10 \mathrm{AT}$ & 172 & 0,90 & 4,61 & 0,98 \\
\hline 26 DE/17AT & 176 & 0,90 & 4,64 & 0,98 \\
\hline \multicolumn{5}{|c|}{ Tratamento T10 } \\
\hline Ano C/T & $S$ & J' & $\mathrm{H}^{\prime}$ & $1-\mathrm{D}$ \\
\hline 1AE & 139 & 0,90 & 4,42 & 0,98 \\
\hline 1DE & 136 & 0,90 & 4,41 & 0,98 \\
\hline 3 DE & 137 & 0,90 & 4,44 & 0,98 \\
\hline $5 \mathrm{DE}$ & 140 & 0,90 & 4,46 & 0,98 \\
\hline 9 DE & 144 & 0,90 & 4,47 & 0,98 \\
\hline 11 DE/2DT & 147 & 0,89 & 4,44 & 0,98 \\
\hline $19 \mathrm{DE} / 10 \mathrm{AT}$ & 160 & 0,89 & 4,53 & 0,98 \\
\hline $26 \mathrm{DE} / 17 \mathrm{AT}$ & 177 & 0,89 & 4,63 & 0,98 \\
\hline \multicolumn{5}{|c|}{ Tratamento T11 } \\
\hline Ano C/T & $S$ & J' & $\mathrm{H}^{\prime}$ & 1-D \\
\hline $\mathbf{1 A E}$ & 137 & 0,88 & 4,35 & 0,98 \\
\hline 1DE & 133 & 0,89 & 4,35 & 0,98 \\
\hline 3 DE & 132 & 0,90 & 4,38 & 0,98 \\
\hline $5 \mathrm{DE}$ & 131 & 0,90 & 4,37 & 0,98 \\
\hline $9 \mathrm{DE}$ & 137 & 0,90 & 4,40 & 0,98 \\
\hline $11 \mathrm{DE} / 2 \mathrm{DT}$ & 121 & 0,89 & 4,29 & 0,98 \\
\hline $19 \mathrm{DE} / 10 \mathrm{AT}$ & 149 & 0,90 & 4,51 & 0,98 \\
\hline $26 \mathrm{DE} / 17 \mathrm{AT}$ & 160 & 0,90 & 4,58 & 0,98 \\
\hline \multicolumn{5}{|c|}{ Tratamento T12 } \\
\hline Ano C/T & $\mathrm{S}$ & $\mathrm{J}$ & $\mathrm{H}^{\prime}$ & 1-D \\
\hline 1AE & 136 & 0,89 & 4,35 & 0,98 \\
\hline 1DE & 135 & 0,89 & 4,36 & 0,98 \\
\hline 3 DE & 133 & 0,89 & 4,35 & 0,98 \\
\hline $5 \mathrm{DE}$ & 132 & 0,89 & 4,35 & 0,98 \\
\hline $9 \mathrm{DE}$ & 138 & 0,90 & 4,42 & 0,98 \\
\hline $11 \mathrm{DE} / 2 \mathrm{DT}$ & 148 & 0,90 & 4,48 & 0,98 \\
\hline $19 \mathrm{DE} / 10 \mathrm{AT}$ & 169 & 0,90 & 4,61 & 0,98 \\
\hline $26 \mathrm{DE} / 17 \mathrm{AT}$ & 173 & 0,90 & 4,64 & 0,98 \\
\hline
\end{tabular}

Fonte: Autores.

\section{Floresta do Moju}

Quanto a riqueza de espécies absoluta verificou-se que dois anos antes da exploração a área possuía 239 espécies e um ano após a exploração a mesma ficou com 233 espécies. A equabilidade para este período continuou a mesma nesta floresta, o seu índice de Shanon e de Simpson também não mudaram um ano após a exploração (Tabela 11).

Treze anos após a exploração esta área já tinha superado em três unidades o número de espécies de antes da exploração. A Equabilidade durante este mesmo período continuou o mesmo do período anterior, porém o índice de diversidade de Shanon aumentou e o índice de diversidade de Simpson continuou o mesmo. 
Dezoito anos após a exploração florestal esta área estava com nove espécies a mais que antes da exploração. E quanto a Equabilidade durante este mesmo por todo o período de observação, porém o índice de diversidade de Shanon aumentou de 4,47 para 4,30 e o índice de diversidade de Simpson continuou o mesmo $(0,96)$.

Tabela 11. Riqueza (S), Índice de Shannon (H'), Índice máximo de Shanon (H'max), equabilidade(J'), Índice de dominância de Simpson (D) e Índice diversidade Simpson (1-D) na área experimental do Moju.

\begin{tabular}{ccccc}
\hline Ano Colheita & S & J' & H' $^{\prime}$ & $1-\mathrm{D}$ \\
\hline 2 AE & 239 & 0,78 & 4,27 & 0,96 \\
$1 \mathrm{DE}$ & 233 & 0,78 & 4,27 & 0,96 \\
$13 \mathrm{DE}$ & 242 & 0,78 & 4,29 & 0,96 \\
$18 \mathrm{DE}$ & 248 & 0,78 & 4,30 & 0,96 \\
\hline
\end{tabular}

Fonte: Autores.

\section{Área do PETECO na fazenda Rio capim}

Quanto a riqueza de espécies absoluta verificou-se que antes da exploração, a área possuía 158 espécies no tratamento T0, 146 no tratamento T1 e 139 no tratamento T2, porém um ano após a exploração a mesma teve uma diminuição de espécies para os tratamentos em que houve a exploração (T1 e T2). A Equabilidade para este período continuou a mesma no tratamento T1 e diminuiu nos tratamentos T0 e T2. O índice de Shanon ficou o mesmo para o tratamento T0 e diminuiu para os tratamentos T1 e T2, o índice de Simpson continuou o mesmo em todos os tratamentos para este período (Tabela 12).

Oito anos após a exploração está área não recuperou o número de espécies que tinha antes da exploração florestal de baixo impacto, inclusive no T0. Quanto ao índice de Equabilidade continua o mesmo para o tratamento T1, porém para os outros tratamentos teve uma diminuição em seu valor. O índice de Shanon diminuiu em todos os tratamentos e o índice de Simpson continua o mesmo por todo o período de monitoramento.

Tabela 12: Riqueza (S), Índice de Shannon (H'), Índice máximo de Shanon (H'max), equabilidade(J'), Índice de dominância de Simpson (D) e Índice diversidade Simpson (1-D) na área experimental do Peteco.

\begin{tabular}{|c|c|c|c|c|}
\hline \multicolumn{5}{|c|}{ Tratamento T0 } \\
\hline Ano Colheita & $S$ & $\mathrm{~J}$ & $\mathrm{H}^{\prime}$ & 1-D \\
\hline $\mathrm{AE}$ & 158 & 0,88 & 4,43 & 0,98 \\
\hline $1 \mathrm{DE}$ & 158 & 0,87 & 4,43 & 0,98 \\
\hline $2 \mathrm{DE}$ & 153 & 0,87 & 4,39 & 0,98 \\
\hline $4 \mathrm{DE}$ & 153 & 0,87 & 4,39 & 0,98 \\
\hline $5 \mathrm{DE}$ & 157 & 0,87 & 4,41 & 0,98 \\
\hline $8 \mathrm{DE}$ & 157 & 0,86 & 4,36 & 0,98 \\
\hline \multicolumn{5}{|c|}{ Tratamento T1 } \\
\hline Ano Colheita & $S$ & $\mathrm{~J}$ & $\mathrm{H}^{\prime}$ & 1-D \\
\hline $\mathrm{AE}$ & 146 & 0,88 & 4,39 & 0,98 \\
\hline $1 \mathrm{DE}$ & 143 & 0,88 & 4,37 & 0,98 \\
\hline $2 \mathrm{DE}$ & 142 & 0,88 & 4,36 & 0,98 \\
\hline $4 \mathrm{DE}$ & 142 & 0,88 & 4,36 & 0,98 \\
\hline $5 \mathrm{DE}$ & 140 & 0,88 & 4,34 & 0,98 \\
\hline $8 \mathrm{DE}$ & 144 & 0,88 & 4,38 & 0,98 \\
\hline \multicolumn{5}{|c|}{ Tratamento T2 } \\
\hline Ano Colheita & $S$ & $\mathrm{~J}$ & $\mathrm{H}^{\prime}$ & $1-\mathrm{D}$ \\
\hline $\mathrm{AE}$ & 139 & 0,88 & 4,33 & 0,98 \\
\hline $1 \mathrm{DE}$ & 132 & 0,87 & 4,27 & 0,98 \\
\hline $2 \mathrm{DE}$ & 130 & 0,88 & 4,26 & 0,98 \\
\hline $4 \mathrm{DE}$ & 132 & 0,87 & 4,26 & 0,98 \\
\hline $5 \mathrm{DE}$ & 131 & 0,87 & 4,26 & 0,98 \\
\hline $8 \mathrm{DE}$ & 127 & 0,87 & 4,23 & 0,98 \\
\hline
\end{tabular}

Fonte: Autores. 


\section{Índice de Bray Curts}

\section{Km 114 da Flona do Tapajós}

Nesta área foi observado que o tratamento T0 sem passar pela exploração florestal cinco anos após a primeira medição encontrava-se $96 \%$ similar a primeira medição, permanecendo com esse valor até o final dos trinta anos de observação. Após o fogo, que queimou metade dos blocos desse tratamento a floresta ficou $81 \%$ similar a floresta medida anteriormente (Tabela 13).

O Tratamento T1, após a exploração florestal ficou 98\% diferente da floresta anteriormente medida, após o fogo que queimou somente dois blocos desse tratamento o mesmo ficou $76 \%$ similar com a medição anterior ao fogo. No final das medições a floresta se encontra $66 \%$ similar a floresta antes da exploração.

O tratamento T2, após a exploração ficou $97 \%$ similar ao ano anterior a exploração, depois dos tratamentos silviculturais a floresta ficou 92\% similar a medição anterior, após o fogo que queimou 5 blocos desse tratamento o mesmo ficou 78\% similar a floresta que tinha anteriormente. Após os 30 anos com todos esses fatores a floresta ficou 77\% similar a floresta antes da exploração florestal.

O tratamento T3, após a exploração ficou $97 \%$ similar ao ano anterior a exploração, depois dos tratamentos silviculturais a floresta ficou $94 \%$ similar a medição anterior. Após os 30 anos com todos esses fatores a floresta ficou $60 \%$ similar a floresta antes da exploração florestal.

O tratamento T4, após a exploração ficou $96 \%$ similar ao ano anterior a exploração, depois dos tratamentos silviculturais a floresta ficou 91\% similar a medição anterior, após o fogo que queimou 6 blocos desse tratamento o mesmo ficou 53\% similar a floresta que tinha anteriormente. Após os 30 anos com todos esses fatores a floresta ficou 47\% similar a floresta antes da exploração florestal.

Tabela 13. Índice de similaridade de Bray- Curtis para os tratamentos no km 114 da Floresta nacional do Tapajós, Belterra, Pará.

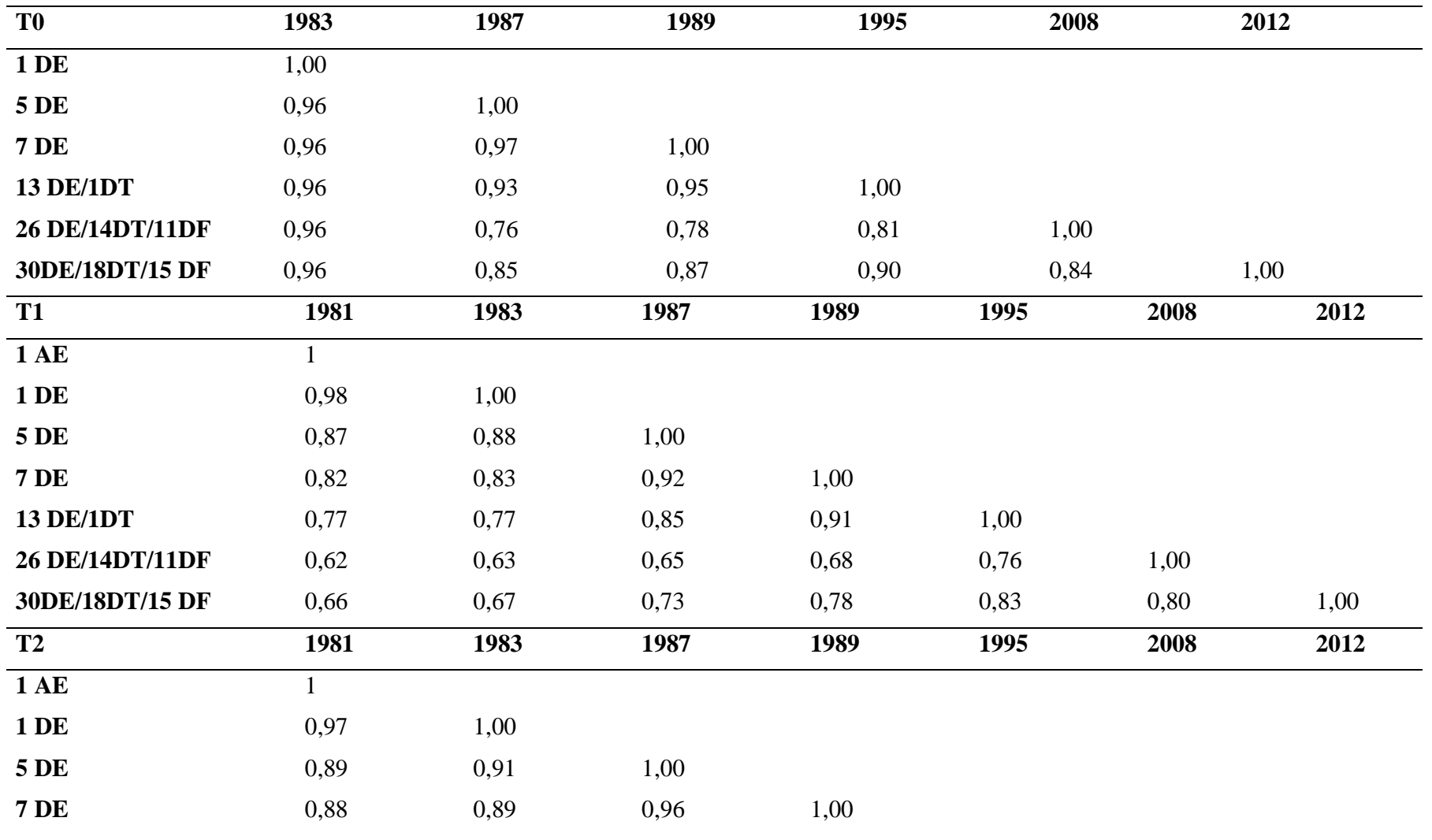




\begin{tabular}{|c|c|c|c|c|c|c|c|}
\hline 13 DE/1DT & 0,83 & 0,85 & 0,90 & 0,92 & 1,00 & & \\
\hline 26 DE/14DT/11DF & 0,68 & 0,70 & 0,71 & 0,72 & 0,78 & 1,00 & \\
\hline 30DE/18DT/15 DF & 0,77 & 0,79 & 0,82 & 0,84 & 0,89 & 0,83 & 1,00 \\
\hline T3 & 1981 & 1983 & 1987 & 1989 & 1995 & 2008 & 2012 \\
\hline $1 \mathrm{AE}$ & 1 & & & & & & \\
\hline $1 \mathrm{DE}$ & 0,97 & 1,00 & & & & & \\
\hline $5 \mathrm{DE}$ & 0,89 & 0,91 & 1,00 & & & & \\
\hline $7 \mathrm{DE}$ & 0,86 & 0,87 & 0,94 & 1,00 & & & \\
\hline 13 DE/1DT & 0,83 & 0,84 & 0,89 & 0,94 & 1,00 & & \\
\hline 26 DE/14DT/11DF & 0,58 & 0,59 & 0,61 & 0,61 & 0,65 & 1,00 & \\
\hline 30DE/18DT/15 DF & 0,60 & 0,61 & 0,64 & 0,64 & 0,69 & 0,78 & 1,00 \\
\hline T4 & 1981 & 1983 & 1987 & 1989 & 1995 & 2008 & 2012 \\
\hline $1 \mathbf{A E}$ & 1 & & & & & & \\
\hline $1 \mathrm{DE}$ & 0,96 & 1,00 & & & & & \\
\hline $5 \mathrm{DE}$ & 0,89 & 0,90 & 1,00 & & & & \\
\hline $7 \mathrm{DE}$ & 0,83 & 0,85 & 0,92 & 1,00 & & & \\
\hline 13 DE/1DT & 0,78 & 0,81 & 0,86 & 0,91 & 1,00 & & \\
\hline 26 DE/14DT/11DF & 0,48 & 0,50 & 0,49 & 0,49 & 0,53 & 1,00 & \\
\hline 30DE/18DT/15 DF & 0,47 & 0,48 & 0,49 & 0,49 & 0,54 & 0,72 & 1,00 \\
\hline
\end{tabular}

Fonte: Autores.

\section{Companhia Florestal Monte Dourado- Jari}

Observando os fatores que ocorreram com essa área como exploração e tratamentos silviculturais, observamos que o tratamento T0, após 26 anos de observação sem exploração e sem tratamentos silviculturais está 82\% similar a floresta do começo das medições (Tabela 14).

Quanto aos tratamentos que tiveram explorações florestal de impacto reduzido, após a exploração ficaram com os valores de 98 a $99 \%$ similares ao ano anterior a exploração, depois dos tratamentos silviculturais os tratamentos que tiveram o mesmo como o T2, T3, T4, T6, T7, T8, T10, T11 e T12 ficaram com valores de 94 a 97\% similar a medição de antes dos tratamentos silviculturais. Após os 26 anos de observação, os tratamentos T1, T5 e T9, que tiveram somente exploração florestal sem tratamentos silviculturais, ficaram com $80 \%, 77 \%$ e $78 \%$ similares com a floresta antes da exploração florestal, e os tratamentos que tiveram exploração e tratamentos silviculturais, ficaram com $71 \%$ a $80 \%$ similares ao valor calculado de antes da exploração.

Tabela 14: Índice de similaridade de Bray- Curtis para os tratamentos da área experimental do Jari.

\begin{tabular}{|c|c|c|c|c|c|c|c|c|}
\hline T0 & 1984 & 1986 & 1988 & 1990 & 1994 & 1996 & 2004 & 2011 \\
\hline 1AE & 1,00 & & & & & & & \\
\hline 1DE & 0,98 & 1,00 & & & & & & \\
\hline 3 DE & 0,98 & 0,99 & 1,00 & & & & & \\
\hline $5 \mathrm{DE}$ & 0,97 & 0,98 & 0,99 & 1,00 & & & & \\
\hline 9 DE & 0,94 & 0,94 & 0,95 & 0,96 & 1,00 & & & \\
\hline $11 \mathrm{DE} / 2 \mathrm{DT}$ & 0,92 & 0,92 & 0,93 & 0,93 & 0,97 & 1,00 & & \\
\hline $19 \mathrm{DE} / 10 \mathrm{AT}$ & 0,87 & 0,88 & 0,88 & 0,89 & 0,92 & 0,94 & 1,00 & \\
\hline 26 DE/17AT & 0,82 & 0,83 & 0,83 & 0,84 & 0,87 & 0,88 & 0,92 & 1,00 \\
\hline T1 & 1984 & 1986 & 1988 & 1990 & 1994 & 1996 & 2004 & 2011 \\
\hline 1AE & 1 & & & & & & & \\
\hline 1DE & 0,99 & 1,00 & & & & & & \\
\hline 3 DE & 0,96 & 0,97 & 1,00 & & & & & \\
\hline $5 \mathrm{DE}$ & 0,93 & 0,94 & 0,97 & 1,00 & & & & \\
\hline
\end{tabular}




\begin{tabular}{|c|c|c|c|c|c|c|c|c|}
\hline $9 \mathrm{DE}$ & 0,90 & 0,90 & 0,92 & 0,95 & 1,00 & & & \\
\hline 11 DE/2DT & 0,88 & 0,89 & 0,90 & 0,93 & 0,97 & 1,00 & & \\
\hline 19 DE/10AT & 0,84 & 0,85 & 0,86 & 0,88 & 0,92 & 0,93 & 1,00 & \\
\hline $26 \mathrm{DE} / 17 \mathrm{AT}$ & 0,80 & 0,80 & 0,81 & 0,83 & 0,87 & 0,88 & 0,94 & 1,00 \\
\hline T2 & 1984 & 1986 & 1988 & 1990 & 1994 & 1996 & 2004 & 2011 \\
\hline $1 \mathrm{AE}$ & 1 & & & & & & & \\
\hline 1DE & 0,98 & 1,00 & & & & & & \\
\hline 3 DE & 0,94 & 0,95 & 1,00 & & & & & \\
\hline $5 \mathrm{DE}$ & 0,93 & 0,94 & 0,98 & 1,00 & & & & \\
\hline $9 \mathrm{DE}$ & 0,91 & 0,91 & 0,94 & 0,96 & 1,00 & & & \\
\hline 11 DE/2DT & 0,89 & 0,89 & 0,91 & 0,93 & 0,96 & 1,00 & & \\
\hline $19 \mathrm{DE} / 10 \mathrm{AT}$ & 0,84 & 0,85 & 0,86 & 0,87 & 0,89 & 0,92 & 1,00 & \\
\hline $26 \mathrm{DE} / 17 \mathrm{AT}$ & 0,81 & 0,82 & 0,83 & 0,85 & 0,87 & 0,89 & 0,94 & 1,00 \\
\hline T3 & 1984 & 1986 & 1988 & 1990 & 1994 & 1996 & 2004 & 2011 \\
\hline $1 \mathrm{AE}$ & 1 & & & & & & & \\
\hline 1DE & 0,98 & 1,00 & & & & & & \\
\hline 3 DE & 0,95 & 0,97 & 1,00 & & & & & \\
\hline $5 \mathrm{DE}$ & 0,94 & 0,95 & 0,97 & 1,00 & & & & \\
\hline $9 \mathrm{DE}$ & 0,91 & 0,92 & 0,93 & 0,95 & 1,00 & & & \\
\hline $11 \mathrm{DE} / 2 \mathrm{DT}$ & 0,89 & 0,91 & 0,91 & 0,92 & 0,97 & 1,00 & & \\
\hline 19 DE/10AT & 0,83 & 0,83 & 0,83 & 0,84 & 0,87 & 0,88 & 1,00 & \\
\hline $26 \mathrm{DE} / 17 \mathrm{AT}$ & 0,79 & 0,79 & 0,79 & 0,81 & 0,82 & 0,84 & 0,93 & 1,00 \\
\hline T4 & 1984 & 1986 & 1988 & 1990 & 1994 & 1996 & 2004 & 2011 \\
\hline $1 \mathrm{AE}$ & 1 & & & & & & & \\
\hline 1DE & 0,99 & 1,00 & & & & & & \\
\hline $3 \mathrm{DE}$ & 0,96 & 0,98 & 1,00 & & & & & \\
\hline $5 \mathrm{DE}$ & 0,94 & 0,96 & 0,98 & 1,00 & & & & \\
\hline $9 \mathrm{DE}$ & 0,91 & 0,92 & 0,94 & 0,95 & 1,00 & & & \\
\hline $11 \mathrm{DE} / 2 \mathrm{DT}$ & 0,88 & 0,89 & 0,91 & 0,93 & 0,97 & 1,00 & & \\
\hline $19 \mathrm{DE} / 10 \mathrm{AT}$ & 0,83 & 0,84 & 0,85 & 0,86 & 0,88 & 0,89 & 1,00 & \\
\hline $26 \mathrm{DE} / 17 \mathrm{AT}$ & 0,78 & 0,79 & 0,80 & 0,80 & 0,83 & 0,83 & 0,92 & 1,00 \\
\hline T5 & 1984 & 1986 & 1988 & 1990 & 1994 & 1996 & 2004 & 2011 \\
\hline $1 \mathrm{AE}$ & 1 & & & & & & & \\
\hline 1DE & 0,98 & 1,00 & & & & & & \\
\hline 3 DE & 0,94 & 0,95 & 1,00 & & & & & \\
\hline $5 \mathrm{DE}$ & 0,92 & 0,93 & 0,97 & 1,00 & & & & \\
\hline $9 \mathrm{DE}$ & 0,88 & 0,89 & 0,92 & 0,94 & 1,00 & & & \\
\hline $11 \mathrm{DE} / 2 \mathrm{DT}$ & 0,87 & 0,87 & 0,90 & 0,92 & 0,97 & 1,00 & & \\
\hline $19 \mathrm{DE} / 10 \mathrm{AT}$ & 0,80 & 0,81 & 0,82 & 0,83 & 0,88 & 0,90 & 1,00 & \\
\hline $26 \mathrm{DE} / 17 \mathrm{AT}$ & 0,77 & 0,78 & 0,78 & 0,80 & 0,84 & 0,86 & 0,94 & 1,00 \\
\hline T6 & 1984 & 1986 & 1988 & 1990 & 1994 & 1996 & 2004 & 2011 \\
\hline $1 \mathrm{AE}$ & 1 & & & & & & & \\
\hline 1DE & 0,99 & 1,00 & & & & & & \\
\hline 3 DE & 0,94 & 0,95 & 1,00 & & & & & \\
\hline $5 \mathrm{DE}$ & 0,92 & 0,92 & 0,97 & 1,00 & & & & \\
\hline $9 \mathrm{DE}$ & 0,88 & 0,88 & 0,92 & 0,95 & 1,00 & & & \\
\hline $11 \mathrm{DE} / 2 \mathrm{DT}$ & 0,87 & 0,87 & 0,90 & 0,93 & 0,97 & 1,00 & & \\
\hline $19 \mathrm{DE} / 10 \mathrm{AT}$ & 0,82 & 0,82 & 0,85 & 0,85 & 0,88 & 0,90 & 1,00 & \\
\hline $26 \mathrm{DE} / 17 \mathrm{AT}$ & 0,77 & 0,77 & 0,80 & 0,80 & 0,83 & 0,85 & 0,91 & 1,00 \\
\hline$\overline{T 7}$ & 1984 & 1986 & 1988 & 1990 & 1994 & 1996 & 2004 & 2011 \\
\hline 1AE & 1 & & & & & & & \\
\hline 1DE & 0,99 & 1,00 & & & & & & \\
\hline 3 DE & 0,94 & 0,95 & 1,00 & & & & & \\
\hline $5 \mathrm{DE}$ & 0,92 & 0,92 & 0,97 & 1,00 & & & & \\
\hline $9 \mathrm{DE}$ & 0,88 & 0,88 & 0,93 & 0,94 & 1,00 & & & \\
\hline $11 \mathrm{DE} / 2 \mathrm{DT}$ & 0,86 & 0,86 & 0,90 & 0,92 & 0,97 & 1,00 & & \\
\hline 19 DE/10AT & 0,79 & 0,79 & 0,82 & 0,83 & 0,86 & 0,88 & 1,00 & \\
\hline $26 \mathrm{DE} / 17 \mathrm{AT}$ & 0,73 & 0,73 & 0,76 & 0,77 & 0,79 & 0,80 & 0,89 & 1,00 \\
\hline
\end{tabular}




\begin{tabular}{|c|c|c|c|c|c|c|c|c|}
\hline T8 & 1984 & 1986 & 1988 & 1990 & 1994 & 1996 & 2004 & 2011 \\
\hline 1AE & 1 & & & & & & & \\
\hline 1DE & 0,98 & 1,00 & & & & & & \\
\hline 3 DE & 0,93 & 0,94 & 1,00 & & & & & \\
\hline $5 \mathrm{DE}$ & 0,90 & 0,91 & 0,96 & 1,00 & & & & \\
\hline $9 \mathrm{DE}$ & 0,88 & 0,88 & 0,88 & 0,95 & 1,00 & & & \\
\hline $11 \mathrm{DE} / 2 \mathrm{DT}$ & 0,85 & 0,85 & 0,85 & 0,91 & 0,95 & 1,00 & & \\
\hline 19 DE/10AT & 0,78 & 0,78 & 0,78 & 0,81 & 0,85 & 0,87 & 1,00 & \\
\hline $26 \mathrm{DE} / 17 \mathrm{AT}$ & 0,72 & 0,71 & 0,71 & 0,74 & 0,77 & 0,80 & 0,89 & 1,00 \\
\hline T9 & 1984 & 1986 & 1988 & 1990 & 1994 & 1996 & 2004 & 2011 \\
\hline$\overline{1 A E}$ & 1 & & & & & & & \\
\hline 1DE & 0,99 & 1,00 & & & & & & \\
\hline $3 \mathrm{DE}$ & 0,94 & 0,95 & 1,00 & & & & & \\
\hline $5 \mathrm{DE}$ & 0,91 & 0,92 & 0,96 & 1,00 & & & & \\
\hline $9 \mathrm{DE}$ & 0,89 & 0,90 & 0,92 & 0,95 & 1,00 & & & \\
\hline $11 \mathrm{DE} / 2 \mathrm{DT}$ & 0,87 & 0,88 & 0,91 & 0,92 & 0,96 & 1,00 & & \\
\hline 19 DE/10AT & 0,81 & 0,83 & 0,84 & 0,85 & 0,89 & 0,91 & 1,00 & \\
\hline $26 \mathrm{DE} / 17 \mathrm{AT}$ & 0,78 & 0,79 & 0,80 & 0,81 & 0,84 & 0,86 & 0,94 & 1,00 \\
\hline T10 & 1984 & 1986 & 1988 & 1990 & 1994 & 1996 & 2004 & 2011 \\
\hline $1 \mathrm{AE}$ & 1 & & & & & & & \\
\hline $1 D E$ & 0,98 & 1,00 & & & & & & \\
\hline 3 DE & 0,91 & 0,93 & 1,00 & & & & & \\
\hline $5 \mathrm{DE}$ & 0,88 & 0,90 & 0,96 & 1,00 & & & & \\
\hline $9 \mathrm{DE}$ & 0,85 & 0,86 & 0,90 & 0,93 & 1,00 & & & \\
\hline $11 \mathrm{DE} / 2 \mathrm{DT}$ & 0,81 & 0,82 & 0,85 & 0,88 & 0,94 & 1,00 & & \\
\hline $19 \mathrm{DE} / 10 \mathrm{AT}$ & 0,75 & 0,76 & 0,78 & 0,80 & 0,85 & 0,89 & 1,00 & \\
\hline $26 \mathrm{DE} / 17 \mathrm{AT}$ & 0,71 & 0,72 & 0,73 & 0,76 & 0,80 & 0,83 & 0,91 & 1,00 \\
\hline$\overline{T \text { T11 }}$ & 1984 & 1986 & 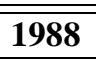 & 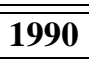 & 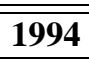 & 1996 & 2004 & $\overline{2011}$ \\
\hline $1 \mathrm{AE}$ & 1 & & & & & & & \\
\hline 1DE & 0,99 & 1,00 & & & & & & \\
\hline 3 DE & 0,93 & 0,94 & 1,00 & & & & & \\
\hline $5 \mathrm{DE}$ & 0,90 & 0,91 & 0,97 & 1,00 & & & & \\
\hline $9 \mathrm{DE}$ & 0,85 & 0,86 & 0,89 & 0,92 & 1,00 & & & \\
\hline $11 \mathrm{DE} / 2 \mathrm{DT}$ & 0,83 & 0,83 & 0,88 & 0,90 & 0,97 & 1,00 & & \\
\hline 19 DE/10AT & 0,75 & 0,76 & 0,78 & 0,79 & 0,82 & 0,83 & 1,00 & \\
\hline $26 \mathrm{DE} / 17 \mathrm{AT}$ & 0,72 & 0,72 & 0,73 & 0,73 & 0,77 & 0,77 & 0,89 & 1,00 \\
\hline$\overline{T 12}$ & 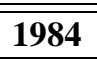 & 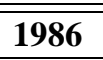 & 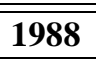 & 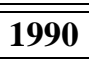 & 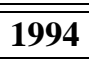 & 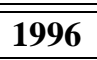 & 2004 & $\overline{2011}$ \\
\hline $1 \mathrm{AE}$ & 1 & & & & & & & \\
\hline 1DE & 0,98 & 1,00 & & & & & & \\
\hline 3 DE & 0,92 & 0,94 & 1,00 & & & & & \\
\hline $5 \mathrm{DE}$ & 0,90 & 0,92 & 0,97 & 1,00 & & & & \\
\hline $9 \mathrm{DE}$ & 0,87 & 0,89 & 0,92 & 0,94 & 1,00 & & & \\
\hline $11 \mathrm{DE} / 2 \mathrm{DT}$ & 0,83 & 0,85 & 0,88 & 0,90 & 0,95 & 1,00 & & \\
\hline 19 DE/10AT & 0,78 & 0,80 & 0,81 & 0,83 & 0,87 & 0,89 & 1,00 & \\
\hline $26 \mathrm{DE} / 17 \mathrm{AT}$ & 0,75 & 0,77 & 0,78 & 0,79 & 0,84 & 0,85 & 0,94 & 1,00 \\
\hline
\end{tabular}

Fonte: Autores.

\section{Floresta do Moju}

Observando o fator exploração de impacto reduzido que aconteceu nessa área, observamos que após a exploração a mesma ficou $96 \%$ similar ao ano anterior a exploração. Após os 18 anos de observação a floresta está 78\% similar a floresta antes da exploração (Tabela 15). 
Tabela 15. Índice de similaridade de Bray-Curtis para a área experimental do Moju.

\begin{tabular}{lllll}
\hline Moju & $\mathbf{1 9 9 5}$ & $\mathbf{1 9 9 8}$ & $\mathbf{2 0 1 0}$ & $\mathbf{2 0 1 5}$ \\
\hline $\mathbf{2} \mathbf{A E}$ & 1 & & & \\
$\mathbf{1 D E}$ & 0,96 & 1 & 1 & \\
$\mathbf{1 3 D E}$ & 0,80 & 0,84 & 0,91 & 1 \\
$\mathbf{1 8 D E}$ & 0,78 & 0,82 & & \\
\hline
\end{tabular}

\section{PETECO na fazenda Rio capim}

Fonte: Autores.

Observando o fator exploração que aconteceu com os tratamentos dessa área podemos constatar que, o tratamento T0 de um ano para o outro ficou diferente $1 \%$, enquanto que os tratamentos que tiveram a exploração (T1 e T2) ficaram com $95 \%$ e 93\% respectivamente similares a área antes da exploração. Após 8 anos de observação o tratamento T0 está $78 \%$ similar a floresta do primeiro ano de observação e os tratamentos T1 e T2 que tiveram exploração estão 89 e $87 \%$ respectivamente, similares a floresta antes da exploração (Tabela 16).

Tabela 16. Índice de similaridade de Bray- curtis para os tratamentos da área experimental do Peteco.

\begin{tabular}{|c|c|c|c|c|c|c|}
\hline T0 & 2003 & 2004 & 2005 & 2007 & 2008 & 2011 \\
\hline $\mathbf{A E}$ & 1 & & & & & \\
\hline 1DE & 0,99 & 1 & & & & \\
\hline 2DE & 0,97 & 0,98 & 1 & & & \\
\hline 4DE & 0,94 & 0,95 & 0,95 & 1 & & \\
\hline 5DE & 0,94 & 0,95 & 0,95 & 0,96 & 1 & \\
\hline 8DE & 0,90 & 0,91 & 0,91 & 0,93 & 0,93 & 1 \\
\hline T1 & 22003 & 2004 & 2005 & 2007 & 2008 & 2011 \\
\hline $\mathbf{A E}$ & 1 & & & & & \\
\hline $1 \mathrm{DE}$ & 0,95 & 1 & & & & \\
\hline 2DE & 0,94 & 0,93 & 1 & & & \\
\hline $4 \mathrm{DE}$ & 0,93 & 0,93 & 0,94 & 1 & & \\
\hline $5 \mathrm{DE}$ & 0,92 & 0,91 & 0,95 & 0,95 & 1 & \\
\hline 8DE & 0,89 & 0,88 & 0,92 & 0,93 & 0,94 & 1 \\
\hline$\overline{T 2}$ & 2003 & 2004 & 2005 & 2007 & 2008 & 2011 \\
\hline $\mathbf{A E}$ & 1 & & & & & \\
\hline $1 \mathrm{DE}$ & 0,93 & 1 & & & & \\
\hline 2DE & 0,93 & 0,91 & 1 & & & \\
\hline 4DE & 0,89 & 0,94 & 0,91 & 1 & & \\
\hline 5DE & 0,91 & 0,91 & 0,94 & 0,93 & 1 & \\
\hline 8DE & 0,87 & 0,89 & 0,91 & 0,92 & 0,95 & 1 \\
\hline
\end{tabular}

Fonte: Autores.

\section{Discussão}

\section{Análise de variância}

Antes da exploração florestal não há diferença estatística entre os tratamentos, porém nos anos após a exploração somente a floresta do peteco não apresentou diferença estatística no decorrer de 8 anos de observação, para as outras áreas a diferença são devido a característica de exploração de cada tratamento. Nas áreas que tiveram tratamentos silviculturais, foi observado que no ano anterior aos desbastes silviculturais, 7 e 9 anos após a exploração, não havia diferença estatística entre os tratamentos e que essa diferença tornou a aparecer depois dos mesmos, e no caso da floresta do Tapajós, também após o fogo, depois de 18 e 17 anos de implantação dos tratamentos silviculturais desapareceu essa diferença estatística. A floresta do Moju evidenciou dois grupos de número médio de espécies, um nos dois primeiros anos de observação com 93,27 e 92,64 respectivamente e outro nos dois últimos anos de observação com um número médio bem maior de espécies, 105,32 e 108,45 respectivamente. Após os 30,26, 18 e 8 anos de medições os tratamentos não tiveram diferenças significativa estatisticamente. 


\section{Riqueza de espécies}

Todos os tratamentos que foram monitorados antes da exploração florestal na área do Tapajós, do Moju e no peteco tiveram perda de espécies após a exploração florestal de impacto reduzido, para a área da floresta do Jari, alguns tratamentos não tiveram essa perda, alguns tiveram aumento neste valor, mostrando que tem explorações que fazem com que surjam espécies um ano após a exploração.

Os tratamentos com exploração aumentam o número de espécies no decorrer do tempo e esse fato é bem mais rápido do que nos tratamentos sem exploração, na floresta do Jari por exemplo dois tratamentos recuperaram em 3 anos. Este fato variou de 03 a 19 anos nesta área.

Após os tratamentos silviculturais foi observado que a perda de espécies é maior que após a exploração florestal, devido a retirada proposital das espécies que não são de interesse econômico para a serraria, porém de grande importância para o equilíbrio florestal.

Após o fogo acidental foi constatado que o mesmo não alterou o número de espécies nos tratamentos em que tiveram o maior número de parcelas com fogo, o único tratamento em que houve uma diminuição no número de espécies foi o tratamento em que não houve tratamentos silviculturais e que teve fogo somente em duas parcelas.

Após 30, 26, 18 e 8 anos de exploração foi observado que a floresta tem uma resiliência forte em relação ao número de espécie devido a recuperação do mesmo durar de 3 a 30 anos pós colheita florestal.

\section{Quanto a equabilidade}

A equabilidade observada em todos os tratamentos variou de 0,82-0,89 na floresta do Tapajós, 0,87 a 0,92 na floresta do Jari, 0,78 na floresta do Moju e 0,86 a 0,88 na floresta do peteco. Mostrando que a representatividade das espécies na comunidade é bem balanceada.

Após a exploração florestal a equabilidade ficou com o mesmo valor para a maioria dos tratamentos, houve um aumento em um tratamento no Tapajós e em três na Jari, e diminuição em um tratamento no Tapajós, nos indicando que a exploração de impacto reduzido não altera a distribuição das espécies nas áreas exploradas.

Após os tratamentos silviculturais a equabilidade aumentou para um tratamento na área do Tapajós e para dois tratamentos no Jari, a mesma diminuiu para um tratamento no tapajós e quatro na floresta do Jari, a equabilidade continuou a mesma para um tratamento no tapajós e quatro no Jari.

Após o fogo na floresta do Tapajós dois tratamentos continuaram com o mesmo valor, um aumentou e um outro diminuiu.

Após os 30, 26, 18 e 8 anos, a equabilidade aumentou para a maioria dos tratamentos, somente teve diminuição em um tratamento no tapajós e outro na Jari, três tratamentos na Jari mantiveram o mesmo valor de antes da colheita, no Moju e no peteco durante todos os anos de observação a equabilidade continuou a mesma.

\section{Diversidade florística}

O índice de Shanon ficou entre 4,07 a 4,52 na floresta do Tapajós, 4,16 a 4,76 no Jari, de 4,27 a 4,30 no Moju e de 4,23 a 4, 43 no Peteco. Mostrando que são florestas com alto índice de diversidade.

Um ano após a exploração foi observado uma queda no índice de diversidade de Shanon para todos os tratamentos em que houve exploração nas áreas do Tapajós e peteco, quatro tratamentos no Jari. Após a exploração, o índice aumentou para a maioria dos tratamentos, diminuindo somente para o tratamento T0 do Tapajós e T0 e T2 do peteco.

Após os tratamentos silviculturais, o índice diminuiu para a maioria dos tratamentos, ficando com o mesmo índice o T2 do Tapajós e T6, T8 e T12 da Jari, e com o aumento o T4 do tapajós e o T2 e T4 do Jari. 
Após os 30, 26, 18 e 8 anos de exploração florestal constatou se que o índice de Shanon ficou maior que antes da exploração florestal para a maioria dos tratamentos, porém para a área do peteco o resultado não foi o mesmo.

Quanto ao índice de Simpson houve diminuição para dois tratamentos no tapajós, manteve-se igual para todos os tratamentos no Jari, Moju e peteco. Durante o período antes dos tratamentos silviculturais este índice aumentou em dois tratamentos no tapajós.

Após a exploração este índice continuou o mesmo para a maioria dos tratamentos, aumentando somente para o T1 e T7 da Jari e diminuindo para o T2 e T4 do Tapajós.

Após os tratamentos silviculturais o índice ficou o mesmo para a maioria dos tratamentos da Jari, diminuindo somente Para os tratamentos T0, T1 e T2, aumentou para os tratamentos T3 e T4 e ficou o mesmo para o T2 do Tapajós.

Após o fogo acidental a maioria dos tratamentos continuaram com o mesmo índice, houve diminuição somente para o tratamento T4.

Após 30, 26, 18 e 8 anos de exploração de impacto reduzido para as áreas estudadas o índice de Simpson continuou o mesmo para a maioria dos tratamentos, diminuindo somente para o tratamento T4 do Tapajós e aumentando para os tratamentos T1, T6, T7e T8 do Jari.

\section{Distância de Bray-Curts}

Foi constatado que a floresta independente do tratamento ela vai mudando a sua característica natural com o tempo, e a exploração florestal acelera essa mudança e que cada tratamento tem a sua participação nesse contexto. Os tratamentos que menos se distanciaram foram os T0s de cada área, que variaram de 78 a $90 \%$ de similaridade após as observações de cada área, e onde as florestas ficaram menos similares com antes da exploração foi na área do km 114 da Flona do Tapajós que teve uma variação de 47 a 77 \% nos tratamentos com exploração.

De modo geral a floresta amazônica brasileira tem uma dinâmica natural que deve ser respeitada, porém a exploração de impacto reduzido é uma ferramenta que acelera essa dinâmica e é uma ferramenta muito eficiente para a manutenção e qualidade da floresta.

\section{Conclusão}

A exploração florestal de impacto reduzido foi menos prejudicial que os tratamentos silviculturais para a manutenção das espécies florestais, 7 a 9 anos para a exploração e 17 a 18 anos após os tratamentos silviculturais.

A floresta recupera o número de espécies de três a 30 anos após a exploração florestal de impacto reduzido, tratamentos silviculturais e fogo.

A equabilidade continua balanceada no decorrer do tempo após a exploração florestal de impacto reduzido, tratamentos silviculturais e fogo.

O índice de Shanon aumenta após a exploração florestal de impacto reduzido, tratamentos silviculturais e fogo. O índice de Simpson continua o mesmo após as intempéries.

A similaridade da floresta muda independente de ter sido uma área explorada ou não, a exploração florestal acelera essa mudança e cada tratamento tem a sua participação nesse contexto.

\section{Agradecimentos}

A Universidade Federal Rural da Amazônia- UFRA, a Embrapa Amazônia Oriental, a Capes, ao CNPQ, aos Pesquisadores, Técnicos e estudantes que de alguma maneira contribuíram para a obtenção desse trabalho. A todos a minha gratidão e respeito. 


\section{Referências}

Alvares, C. A., Stape, J. L., Sentelhas, P. C., Gonçalves, J. L. M., \& Sparovek, G. (2013) Koppen’s climate classification map for Brazil. Meteorologische Zeitschrift, 22(6): 711-728.

Carneiro, F. S., Ruschel, A. R., Oliveira, F. A., Soares, M. H. M., Rodrigues, C. F. A., \& Pinto, M. V. P. (2020). Resiliência da Biomassa Acima do Solo em Áreas Experimentais na Amazônia Oriental. Biodiversidade Brasileira, p. 74-83.

Carneiro, F. S. (2016). Resiliência florestal pós-colheita na Amazônia oriental brasileira. - Belém, 2016.141 f. Tese Doutorado em Ciências Agrárias Universidade Federal Rural da Amazônia, Empresa Brasileira de Pesquisa Agropecuária - EMBRAPA, Belém, 2016. https://ainfo.cnptia.embrapa.br/digital/bitstream/item/175660/1/TeseFinal-FrancimaryCarneiro-08112017.pdf

Carneiro, F. S., Pinheiro, K. A. O., Maestri, M. P., Ruschel, A. R, D’arace, L. M. B., \& Freitas, L. J. M. (2019). Resiliência do volume de madeira de espécies comerciais em diferentes áreas experimentais na Amazônia Oriental. Revista Ibero-americana de Ciências Ambientais, $10,15-31$.

Costa, S. C. C., Jardim, F. C. S, Carneiro, F. S., Amorim, M. B., \& Pinheiro, K. A. O. (2021). Regeneração de Protium pallidum Cuatrec. em clareiras originadas da exploração madeireira seletiva na Amazônia Oriental Brasileira. Research, Society And Development, 10 , e41510313534.

Coutinho, C. H. O., Cruz, H. S., Carneiro, F. S., Souza, C. B. G., \& Viana, J. S. (2021). Geotecnologia aplicada na avaliação de parâmetros fitossociológicos da espécie Handroanthus sp, no Estado do Pará, Brasil. Research, Society And Development, 10, e18210615437.

Henriques, L. M. P., Wunderle, J. M., Oren, D. C, \& Willig, M. R (2008) Efeitos da exploração madeireira de baixo impacto sobre uma comunidade de aves de sub-bosque na floresta Nacional do Tapajós, Pará, Brasil. Acta Amazonica [online]. 38(2). https://doi.org/10.1590/S0044-59672008000200010.

IBGE. (2012). Manual Técnico da Vegetação Brasileira. IBGE. (2a ed.) 272p.

INPE, 2018. INPE registra 6.947 km2 de desmatamento na Amazônia em 2017. http://www.inpe.br/noticias/noticia.php?Cod_Noticia=4778.

Ivanauskas, N. M, \& Assis, M. C. (2012). Formações Florestais Brasileiras. In: Martins, S. V. Ecologia de Florestas Tropicais do Brasil. Viçosa: Editora UFV, 261 p.

Pinheiro, K. A. O., Oliveira, F. A., Ruschel, A. R., Pita, J. D., Santos, G. C., Silva, F. L., Frazão, A. S., Carneiro, F. S., \& Souza, M. F. S. Volumetric space distribution of wood as a tool in sustainable forest. African Journal Of Agricultural Research, 15, 312-322, 2020.

Lima, B. A, Almeida, B. R. S, Sousa, E. A. B, Cruz, G. S, Melo, M. B, Melo, L. O, Costa, D. L, \& Santos, M. F. (2018). Estrutura e dinâmica florestal sob efeito do manejo madeireiro na FLONA Tapajós. Advances in Forestry Science,Cuiabá, 5,.437-443, 2018.

Magurran, A. E. (2011). Medindo a diversidade biológica. Tradução Dana Moiana Vianna. Ed. da UFPR, 261p.

Margalef, R. (1972). Homage to Evelyn Hutchinson, or why is there an upper limit to diversity. Transactions of the Connecticut Academy of Arts and Sciences, 44, 211-235.

Oliveira, L. C. (2005). Efeito da exploração da madeira e de diferentes intensidades de desbastes sobre a dinâmica da vegetação de uma área de 136ha na floresta nacional do Tapajós. Tese Doutorado em Recursos Florestais - Escola Superior de Agricultura Luiz de Queiroz, Universidade de São Paulo, Piracicaba.

Pielou, E. C. (1969). An introduction to mathematical ecology. Wiley.

Pielou, E. C. (1975). Ecological diversity. Wiley InterScience.

Pinheiro, K. A. O., Ruschel, A. R., Carneiro, F. S., Frazão, A. S., Souza, M. F. S, D’Arace, L. M. B., \& Amorim, M. B. (2021). Potencial de espécies comerciais analisado pelo índice de valor de importância em área de exploração de impacto reduzido. Research, Society And Development, 10 , e16610212292.

Rêgo, A. B. M. L., Souza, P. B., Silva, R. R., \& Rêgo, P. L. (2015). Composição florística e estrutural de um componente arbóreo em área de cerrado, Paranã TO. Revista Verde de Agroecologia e Desenvolvimento Sustentável, 10(5): 108 - 114.

Saporetti Jr, A., Meira Neto, J. A., \& Almado, R. P. (2003). Fitossociologia de cerrado sensu stricto no município de Abaeté, MG. Árvore, $27(3)$ ) 413-419.

Schmider, E., Ziegler, M., Danay, E., Beyer, L., \& Bühner, M. (2010). Is it really robust? Reinvestigating the robustness of ANOVA against violations of the normal distribution assumption. Methodology. 6: 147-151. 10.1027/1614-2241/a000016.

Silva, E. J. V. Dinâmica de florestas manejadas e sob exploração convencional na Amazônia oriental -- São Carlos, 2004. Tese Doutorado -- Escola de Engenharia de São Carlos-Universidade de São Paulo, 2004.

Ter Steege, H. et al. 2006. Continental-scale patterns of canopy tree composition and function across Amazonia. Nature. 443, 444-447 